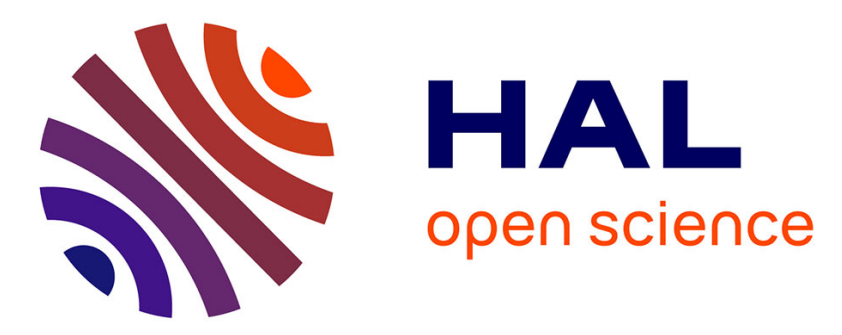

\title{
Development of quantitative Local Electrochemical Impedance Mapping: an efficient tool for the evaluation of delamination kinetics
}

V Shkirskiy, P Volovitch, Vincent Vivier

\section{- To cite this version:}

V Shkirskiy, P Volovitch, Vincent Vivier. Development of quantitative Local Electrochemical Impedance Mapping: an efficient tool for the evaluation of delamination kinetics. Electrochimica Acta, 2017, 235, pp.442-452. 10.1016/j.electacta.2017.03.076 . hal-01498668

\section{HAL Id: hal-01498668 \\ https://hal.science/hal-01498668}

Submitted on 30 Mar 2017

HAL is a multi-disciplinary open access archive for the deposit and dissemination of scientific research documents, whether they are published or not. The documents may come from teaching and research institutions in France or abroad, or from public or private research centers.
L'archive ouverte pluridisciplinaire HAL, est destinée au dépôt et à la diffusion de documents scientifiques de niveau recherche, publiés ou non, émanant des établissements d'enseignement et de recherche français ou étrangers, des laboratoires publics ou privés. 


\title{
Development of quantitative Local Electrochemical Impedance Mapping: an efficient tool for the evaluation of delamination kinetics
}

\author{
V. Shkirskiy ${ }^{\mathrm{b}, 1, *}$, P. Volovitch ${ }^{\mathrm{b}}, \mathrm{V}$. Vivier $^{\mathrm{a}}$ \\ ${ }^{a}$ Sorbonne Universités, UPMC Univ Paris 06, CNRS, Laboratoire Interfaces et Systèmes Electrochimiques, 4 place \\ Jussieu, F-75005, Paris, France \\ ${ }^{b}$ PSL Research University, Institut de Recherche Chimie Paris, CNRS - Chimie-ParisTech, 11 rue Pierre et Marie \\ Curie, Paris 75005, France
}

\begin{abstract}
Local Electrochemical Impedance Mapping (LEIM) methodology was adopted to quantify the propagation of electrochemically active regions with a micrometric precision. The method consisted in the use of the gradient modulus of the admittance map as a parameter for the spatial quantification. Numerical simulations were used to optimize the experimental conditions, namely the AC frequency, the distance between the local bi-probe and the working electrode, and the distances between the probes for the local bi-probe used for the local current mapping. This analysis was reinforced by experimental verifications on coated electrodes. The quantitative LEIM methodology was successfully applied to follow the delamination kinetics on Zn coated with the polyvinyl butyral polymer in $\mathrm{NaCl}$ solutions. At $1 \mathrm{kHz}$, the LEIM response only reflected the position of the anodic front beneath the polymer because oxygen reduction reaction was diffusion limited and hence, independent of the applied potential. This novel LEIM methodology completes the set of usual tools used to investigate the delamination mechanisms on metal substrates.
\end{abstract}

Keywords: LEIM, Numerical simulations, Spatial quantification, Delamination kinetics

\footnotetext{
*Corresponding author

Email address: viacheslav@shkirkiy.org (V. Shkirskiy )
} 


\section{Introduction}

Recently, local electrochemical scanning techniques have attracted a lot of attention due to their ability to resolve macroscopic electrochemical phenomena on nano- and micrometer scales [1-3]. The key parameters of these techniques are (1) the spatial resolution and (2) the spatial quantification i.e. the ability to define the precise geometry and the size of electrochemical regions.

Scanning ElectroChemical Microscopy (SECM) [4-6] and Local Electrochemical Impedance Mapping (LEIM) [7-9] are among the leading techniques competing on these criteria. In the pioneering work, Bard et al. [10] envisioned a possible nanometeric error for the spatial quantification in SECM (i.e. in DC amperometric mode). The compulsory presence of a redox mediator in the solution was required for such a purpose, but recent advances in Alternative-Current Scanning Electrochemical Microscopy (AC-SECM) allowed to eliminate this restriction [1, 2, 11]. The minimal experimental error of the spatial quantification in AC-SECM was in the order of several micrometers achieved on the oriented hematite single crystal surfaces [1]. Conversely, the limits of the spatial quantification of the alternative LEIM methodology have not been well explored.

Several works [12-14] focused on the improvement of the spatial resolution of LEIM technique reporting the spatial resolution of about 30 to $40 \mu \mathrm{m}$ [12]. The main parameters limiting the spatial resolution were $(1)$ the diameter of microelectrode in the bi-probe $(D),(2)$ the distance between the bi-probe and the working electrode (WE) $(h)$, and (3) the distance between the two microelectrodes (d). In ref. [12] these parameters were $D=10 \mu \mathrm{m}, h=25 \mu \mathrm{m}$ and $d=80 \mu \mathrm{mN}$ umerical simulations of the primary potential distribution for a disk electrode embedded in an isolator were in a good agreement with experimental results. In the more recent work [13], a spatial resolution of $35 \mu \mathrm{m}$ was obtained with $D=125 \mu \mathrm{m}, d=250 \mu \mathrm{m}$ and $h=200 \mu \mathrm{m}$.

Even though the spatial resolution in the micrometer range can be reached, the precise size of electrochemically active zones did not match their actual size on the admittance maps in LEIM [7, 15-18]. Moreover, this size was shown to depend on the applied frequency of the AC perturbation [15]. For instance, the apparent size obtained from the admittance maps for a Mo wire of $1.27 \mathrm{~mm}$ in diameter embedded in an $\mathrm{Al}$ matrix was about $3.0 \mathrm{~mm}$ at $4.7 \mathrm{~Hz}$ [15]. This value decreased to approximately $1.88 \mathrm{~mm}$ at $4.7 \mathrm{kHz}$. The size of admittance maps is influenced by the AC frequency because the potential distribution depends on this parameter in the case of nonuniform potential distribution induced by the cell geometry. This phenomenon was first predicted theoretically by Newman [19] for a disk electrode embedded in an isolating plane, then expanded and explained in details for other systems in more recent works [20-25].

In several works, an attempt was made to define the propagation of electroactive zones beneath a 
polymer coating on metal substrates leading to the loss of adhesion (i.e. the position of delamination front) [7, 16-18]. Larger apparent size of the delaminated area from the admittance maps in comparison with the optical observations was always reported in the literature: delamination on the steel/epoxy-vinyl interface scanned at $5 \mathrm{kHz}$ [7], vinyl coating on steel and Al alloy 5182 scanned between 100 and $1 \mathrm{kHz}$ [16], industrial coil coated galvanized steel scanned at $1 \mathrm{kHz}$ [17], epoxy based polymers on Al alloy AA2024-T3 scanned at $700 \mathrm{~Hz}$ [18]. In several works, LEIM revealed the formation of blisters in polymer even before they were visible by an optical technique [16, 18]. The early detection of the electrochemical activity on the metal beneath the organic polymers makes LEIM an appealing tool for the quantitative determination of delamination kinetics. However, to the best of our knowledge no attempt was made to quantitatively correlate the response from the admittance maps and the size of electrochemically active zones.

The aim of the present work is to improve the existent LEIM methodology in order to quantify the precise geometry and the size of electrochemically active regions on the surface of WE. Firstly, the numerical simulations were used to find a parameter for the spatial quantification and then optimize the experimental set-up for such purpose, namely the AC frequency, the distance between the WE and the local bi-probe, and the size of the bi-probe. In the second part of the paper, the novel quantitative LEIM methodology was verified by measuring the delamination kinetics of $\mathrm{Zn}$ covered with the model polyvinyl butyral (PVB) polymer.

\section{Numerical model}

The mathematical foundation for the simulation of the potential and current distributions was adapted from the works by Newman $[19,26]$ originally developed for a planar disk electrode embedded in a coplanar insulator and successfully applied to other cell geometries in order to investigate the edge effect of the electrode on the impedance response [21, 24, 25]. This treatment accounts for both the potential drop due to the ohmic resistance of the media and the electrode polarization.

Fig. 1 shows the geometry of the system used for the simulations. The potential distribution between the WE and the counter electrode $(\mathrm{CE})$ is governed by Laplace equation (see Table 1 for notation):

$$
\nabla^{2} \Phi=0
$$

where $\Phi$ is the potential in the electrochemical cell. In cylindrical coordinates $(r, \theta, y)$, Eq. 1 expresses as 


$$
\frac{1}{r} \frac{\partial}{\partial r}\left(r \frac{\partial \Phi}{\partial r}\right)+\frac{1}{r^{2}} \frac{\partial^{2} \Phi}{\partial \theta^{2}}+\frac{\partial^{2} \Phi}{\partial y^{2}}=0
$$

where $y$ is the axis normal to the electrode surface, $r$ is the radial coordinate and $\theta$ is the azimuth (Fig. 1). The cylindrical symmetry of the system presented in Fig. 1 dictates that $\Phi$ is invariant under rotation, thus

$$
\frac{\partial \Phi}{\partial \theta}=0
$$

leading to

$$
\frac{1}{r} \frac{\partial}{\partial r}\left(r \frac{\partial \Phi}{\partial r}\right)+\frac{\partial^{2} \Phi}{\partial y^{2}}=0
$$

For an alternating current (AC), the electrode potential $V$ can be expressed as

$$
V=V_{0} e^{j w t}
$$

where $V_{0}$ is the amplitude of the applied potential. On the surrounding insulator and far from the electrode surface the boundary conditions are given by Eqs. 6 and 7, respectively

$$
\left.\frac{\partial \Phi}{\partial y}\right|_{y=0}=0 \text { at } r>r_{0}
$$

and

$$
\Phi \rightarrow 0 \text { as } r^{2}+y^{2} \rightarrow \infty
$$

From a numerical point of view, Eq. 7 is satisfied by setting the distance between the CE and the WE 100 times larger than the actual size of the WE (Fig. 1).

The boundary condition at the electrode surface used to describe the electrochemical kinetics at WE was

$$
\frac{\left(V-\Phi_{0}\right)}{R}+C \frac{\partial\left(V-\Phi_{0}\right)}{\partial t}=-\left.\sigma_{s} \frac{\partial \Phi}{\partial y}\right|_{y=0}
$$

where $R$ and $C$ are the values of interfacial resistance and capacitance, respectively, $\sigma_{s}$ is the electrolyte conductivity, and $\Phi_{0}$ is the potential in the solution just ouside of the double layer on the WE. Single $C$ and $R$ were obtained by setting $1 / R$ and $C$ values at zero, respectively. In the case of a constant phase element (CPE) behavior, the governing equations remained the same, the only change was made by substituting $j C w$ by $Q(j w)^{\alpha}$. 
Eq. 8 reflects a parallel combination of the capacitance $C$ of the double layer and the faradaic reaction $R$ on the metal/luquid interface. For all simulations $C$ was set at $50 \mu \mathrm{F} \mathrm{cm} \mathrm{cm}^{-2}$ (typical value for the actively dissolving metals), $\sigma_{s}=0.01 \mathrm{~S} \mathrm{~cm}^{-1}$ and $V_{0}=30 \mathrm{mV}$.

The modulus of the local potential values $\left|\Phi_{1}(r)\right|$ and $\left|\Phi_{2}(r)\right|$ over the WE as a function of the distance from the center of the WE at fixed frequency $f$ were taken as an output of the simulations (see Fig. 1). Then $\left|\Phi_{1}(r)\right|$ and $\left|\Phi_{2}(r)\right|$ were used to calculate the normal component of the local current density, and then local admittance using the conventional data treatment of LEIM data. It is worth noting that in real experiments, the potentials $\left|\Phi_{1}(r)\right|$ and $\left|\Phi_{2}(r)\right|$ are measured with the local bi-microelectrode of finite dimension, i.e. the diameter of each microprobe. Since the normal contribution of the potential distribution should be non-uniform for the electrochemical system in Fig. 1 [20], the measured potentials should be somewhat different from the simulated $\left|\Phi_{1}(r)\right|$ and $\left|\Phi_{2}(r)\right|$ values. However, an excellent correlation between the numerical simulations and the experimental data shows that this difference is negligible (vide infra).

The numerical simulations were carried out using COMSOL Multiphysics ${ }^{\circledR}$ software with the conductive media DC module in a 2D axial symmetry.

\section{Experimental}

\subsection{LEIM technique}

\subsubsection{Electrochemical instrumentation}

The experimental set-up for performing the LEIM measurements consisted of a home-made potentiostat coupled with a lock-in amplifier (5208 Two Phase Lock-in Analyzer, Princeton Applied Research) described in details in Ref. [8]. The WE was fixed as a bottom border of a cylindrical plexiglass home-made electrochemical cell. A conventional three-electrode set-up with a Pt mesh as a counter electrode and an $\mathrm{Ag} / \mathrm{AgCl}$ saturated reference electrode were used to apply $1 \mathrm{kHz}$ with 4 cycles per integration period with $30 \mathrm{mV}$ peak-to-peak potential perturbation. From a practical point of view, $1 \mathrm{kHz}$ is high enough for a fast scanning of the probe above specimen, and low enough to contain any capacitive and/or faradaic contribution of the impedance.

The local probe was positioned so that the center of the closest to WE probe was at $150 \pm 25 \mu \mathrm{m}$ above the WE and moved with a 3-axis positioning system (UTM25, Newport) driven by a motion encoder (MM4005, Newport) with a maximal spatial resolution of $0.2 \mu \mathrm{m}$. All current maps were measured with a step of $100 \mu \mathrm{m}$ along the $y$-direction and with a scan rate of $200 \mu \mathrm{m} / \mathrm{s}$ along the $x$-direction. The typical duration for the acquisition of an LEIM image was about 20 min for 4 mm x $4 \mathrm{~mm}$ scanned area. Single line scans of the current were measured with the resolution of 5 
$\mu \mathrm{m}$ at a scanning rate of $10 \mu \mathrm{m} / \mathrm{s}$ to gain a better resolution, but such values are not realistic for performing the mapping over large surface area.

The potential difference sensed between the two local microelectrodes of the probe was used to calculate the local current density component normal to the surface of WE $\left(i_{l o c}(r)\right)$ :

$$
i_{l o c}(r)=\frac{\left(\Phi_{1}(r)-\Phi_{2}(r)\right) \sigma_{s}}{d}
$$

where $\left(\Phi_{1}(r)-\Phi_{2}(r)\right)$ is the AC potential difference between the two microelectrodes and $d$ is the distance between the center of two microelectrodes. The local impedance was defined as [21]:

$$
z(r)=\frac{V-\Phi_{r e f}}{i_{l o c}(r)}
$$

where $V-\Phi_{\text {ref }}$ represents the AC potential difference between the WE and the RE in the bulk solution. Maps of the local impedance, $z(r)$, or the local admittance, $z^{-1}(r)$, at fixed frequency are the typical output used so far in the literature to report on LEIM experiments [7, 15-18], but in the present work only the local admittance has been used.

\subsubsection{Probe preparation}

It is worth reminding that the commercially available probes for LEIM usually consist in the Pt tip and the surrounding Pt ring of about $1 \mathrm{~mm}$ in diameter that assumes the measurement of the potential over an average surface area of about $3.14 \mathrm{~mm}^{2}$. This set-up reduces significantly the achievable spatial resolution to several microns. To improve the resolution, home-made probes were used in this work [8].

The local probe consisted of two Ag wires of $200 \mu \mathrm{m}$ in diameter, which were sealed in two agglutinated capillaries with $d=500 \mu \mathrm{m}$. The capillaries were bended so that the $\mathrm{Ag}$ electrodes were perpendicular to the surface of WE, and thus, only the normal contribution of the current density was monitored [8]. In addition, the apex of the system was grinded to decrease the size of the probe, which allowed a closest approch of the probe to the WE. Electrochemical deposit of $\mathrm{AgCl}$ was performed by a 5-10 min potentiostatic oxidation of the $\mathrm{Ag}$ in $1 \mathrm{M} \mathrm{KCl}$ on each electrode at 0.5 volt vs $\mathrm{Ag} / \mathrm{AgCl}$ saturated in $\mathrm{KCl}$ reference electrode. Identical impedance values of the microelectrodes measured before and after each set of experiments showed the stability of the local bi-probe.

\subsection{Sample preparation}

All experiments were performed using analytical grade chemicals used as received. Electrolytic solutions were prepared in deionized water (Millipore system ${ }^{\circledR}, 18 \mathrm{M} \Omega \mathrm{cm}$ ). 
Hot dip galvanized steel (HDG) plates (type: HDG/5, supplied by "Chemetall") were used in all experiments. The average thickness of the galvanization layer was about $20 \mu \mathrm{m}$. The plates were cut into $3.5 \mathrm{~cm} \times 3.5 \mathrm{~cm}$ coupons, cleaned with ethanol and water, dried under nitrogen, then immersed in $1 \mathrm{M} \mathrm{NaOH}$ solution at $50^{\circ} \mathrm{C}$ for $30 \mathrm{~s}$, rinsed with water, and dried under nitrogen flow. This treatment was used to remove air-formed corrosion products and to obtain more reproducible surface state (see Ref. [27] for the detailed surface characterization).

In the first configuration, the Zn coupons were covered with an insulating, hydrophobic and impermeable electroplating tape (3M 470, $0.18 \mathrm{~mm}$ thick) with circular holes of different radius (50 $\mathrm{\mu m}-2 \mathrm{~mm}$ ) created by needles of different diameters and a punch belt. The precise radii of the holes were measured with an optical microscope. This set of experiment was designed for the spatial calibration of LEIM. Therefore, only the central part of known size of the Zn surface was exposed to the electrolyte during the local admittance mapping.

For the delamination studies, a disk of $1 \mathrm{~mm}$ radius of the electroplating tape was put at the center of the Zn coupons. The samples were bar casted with $10 \mathrm{w} / \mathrm{w} \%$ solution of PVB (molecular weight 70000-100000, Sigma Aldrich ${ }^{\circledR}$ ) in ethanol. For some experiments, $5 \mathrm{w} / \mathrm{w} \%$ of phenolphtalein (Sigmal Aldrich ${ }^{\circledR}$ ) as pH-indicator was added in the PVB solutions. The samples were dried at air overnight. Then the electroplating plate was gently removed with a needle 100 $\mu \mathrm{m}$ in diameter, leaving the $1 \mathrm{~mm}$ radius hole in the polymer. Profilometry (Nanovea ${ }^{\circledR}$ ) performed around the artificial defect showed that the polymer was about $50 \mu \mathrm{m}$ thick.

In addition, the polarization curves performed on the HDG coupons were similar for two types of surfaces: after alkaline degreasing before application of the adhesive tape and after its application and removing. It excludes the possible influence of the glue from the adhesive tape on the electrochemical response of HDG surface in the artificial defect.

\subsection{Delamination experiments}

Polymer coated HDG samples with the artificial defect of $1 \mathrm{~mm}$ in radius were initially placed in the electrochemical cell and immersed in $30 \mathrm{~mL}$ of $10 \mathrm{mM} \mathrm{NaCl}$ solution for 20 min in order to saturate the polymer coating with water, making possible the ionic flow through the polymer. Then the first scan was performed. If not distinctly mentioned, LEIM experiments were performed at the OCP.

After the first scan, the sample was removed from the electrochemical cell, put in the humidified chamber with relative humidity of $95 \%$ at $23-26^{\circ} \mathrm{C}$, and a $1 \mu \mathrm{L}$ droplet of solution of $0.5 \mathrm{M} \mathrm{NaCl}$ was placed in the artificial defect. The droplet of solution sticked to the edges of the artificial defect due to hydrophobic properties of the PVB film. After approximately $30 \mathrm{~min}$ the droplet of 0.5 
$\mathrm{M} \mathrm{NaCl}$ was removed and the macroscopic image of the surface was taken (time-lapse) with the optical microscope (Carl Zeiss ${ }^{\circledR}$ ). Then the sample was placed again in the electrochemical cell for performing the LEI mapping. The procedure was repeated until the delaminated area visible by optical imaging reached approximately $8 \mathrm{~mm}$ in radius.

The use of diluted $10 \mathrm{mM} \mathrm{NaCl}$ solutions in the electrochemical cell avoided the polymer delamination from Zn during LEIM scans. This was confirmed by the low content of the dissolved Zn after LEIM scan (less than 10 ppb, measured by inductively coupled plasma optical emission spectrometer) and by performing two successive LEIM experiments, which showed identical admittance maps. Therefore, we assume in the following that the delamination of coated HDG substrate occurred only during the exposure time in the humidified atmosphere with the drop of aggressive electrolyte. Thus, the delamination kinetics determined in this work relates to the time of sample exposure in the humidified atmosphere.

\subsection{Surface characterization}

The polymer coating was removed gently with a scalpel from the HDG samples after the delamination experiments. Then, the surface morphology of HDG samples was observed using scanning electron microscope (SEM-FEG Gemini $1530^{\circledR}$ ). Secondary electron contrast images of the top surface were obtained at applied voltage of $5 \mathrm{kV}$.

The surface was also characterized by Raman spectroscopy using Renishaw InVia confocal Raman microscope ${ }^{\circledR}$. Co Diode Pumped Solid State green laser $(532 \mathrm{~nm}$, power of $20 \mathrm{~mW})$ with the edge filter of $>100 \mathrm{~cm}^{-1}$ were used as an excitation source. The objectives with magnification factors of x5, x20, and x50 were used. The accumulation time for individual spectra was $120 \mathrm{~s}$.

\section{Results}

\subsection{Numerical simulations of LEIM experiments}

\subsubsection{Determination of the WE size from admittance maps}

Solid line in Fig. 2 shows the value of the local admittance $z^{-1}(r)$, as a function of the radial distance $r$ from the center of the symmetry corresponding to the electrode center (Fig. 1). The border of LEIM response, where $z^{-1}(r)$ approaches zero, is at about $5 \mathrm{~mm}$ that is 2-3 times larger than the actual radius of the WE (2 mm), which is in a good agreement with the literature [7, 15-18].

A close inspection of $z^{-1}(r)$ shows that the inflection point closely corresponds to $r_{0}$, which can be also clearly seen from the position of the extremum of the first derivative of $z^{-1}(r)$ (red dotted line in Fig. 2). The idea to use the inflection point of a local signal from the electrochemical system 
to define the precise position of the area of the interest originates from the work of Stratmann et al. [28] for the Scanning Kelvin Probe technique. In the following, to avoid any confusion, the symbol $r_{0}$ will be used for the actual radius of the WE and $r_{0}^{\prime}$ for the position corresponding to the extremum of $\delta z^{-1}(r) / \delta r$.

In the following sections the influence of the parameters of the LEIM set-up considered in the introduction part such as the AC frequency and the size of the bi-probe will be revealed on $r_{0}^{\prime}$.

\subsubsection{Influence of the $A C$ frequency on the derivative of local admittance}

A typical illustration of the $z$ variation as a function of $f$ was given by Huang et al. [21] for the example of a blocking electrode. The local impedance was shown to depend not only on $f$ but also on $r_{0}, C$ and $\sigma_{s}$ allowing a dimensionless frequency $K$ to be defined as $[19,21]$

$$
K=\frac{2 \pi f C r_{0}}{\sigma_{s}}
$$

For $1 \leq K \leq 100$ in Ref. [21], the local impedance significantly varied with $K$, whereas for lower and higher values of $K$, it asymptotically approached a constant value. The identical behavior was observed for $r_{0}^{\prime}(K)$ in the present work for the single $C$ in Fig. 3a - curve (1). $r_{0}^{\prime}$ depended on $K$ for $1 \leq K \leq 1000$, but $r_{0}^{\prime} \rightarrow 1.88 \mathrm{~mm}$ when the global impedance of the capacitor $X_{C}=1 / j C w$ tends towards infinity (i.e. when $K \rightarrow 0$ ) and $r_{0}^{\prime} \rightarrow 2.17 \mathrm{~mm}$ when $X_{C}$ approaches zero (i.e. when $K \rightarrow \infty)$. Additionally, an identical behavior was observed when $C$ was replaced by the constant phase element (data not shown).

The behaviour of $r_{0}^{\prime}$ as a function of $R$ shown in Fig. 3b is similar to the variation of $r_{0}^{\prime}(K)$ for the blocking electrode shown in Fig. 3a - curve $(1): r_{0}^{\prime} \rightarrow 1.95 \mathrm{~mm}$ when $R \rightarrow \infty$, whereas $r_{0}^{\prime} \rightarrow 2.17$ $\mathrm{mm}$ when $K \rightarrow 0$. For intermediate values of $\mathrm{R}$, variations of $r_{0}^{\prime}$ are observed. Interestingly, $r_{0}^{\prime}$ approaches exactly the same value of $2.17 \mathrm{~mm}$ at high frequencies in Fig. 3a and low resistances in Fig. 3b even though, different electrode kinetics were applied in these cases.

Curves (2-4) in Fig. 3a show the variations of $r_{0}^{\prime}$ for the Voigt element $(\mathrm{R} / / \mathrm{C})$ as a function of $K$ for the different values of $R$. When $K \rightarrow \infty$, the impedance of capacitor $X_{C} \rightarrow 0$ and thus, the current flows preferably through $C$. In this case the $r_{0}^{\prime}$ behaviour is identical to the one observed for the single $C$ (Fig. 3a curve (1)).

For $K \rightarrow 0$, the impedance of the capacitance $X_{C} \rightarrow \infty$ and thus, the current flows preferably through the $R$ element of the Voigt element. In this case, $r_{0}^{\prime}$ is constant and the precise $r_{0}^{\prime}$ values are identical to those obtained for the single $R$ as shown in Fig. 3b.

These results show that when the influence of the electrode kinetics on the potential distribution can be ignored due to the low value of total impedance, $r_{0}^{\prime}$ approaches the same value of $2.17 \mathrm{~mm}$. 
Interestingly, the analytical solution for the primary potential distribution devised by Newman for a disk electrode embedded in an isolating plane [26] should accurately describe the variations of $\Phi$ expressed in cylindrical coordinates as [29]

$$
\Phi=\frac{2 \Phi_{0}}{\pi} \sin ^{-1}\left(\left(\frac{r}{r_{0}}-1\right)^{2}+2\left(\frac{y}{r_{0}}\right)^{2}+\left(\frac{r}{r_{0}}+1\right)^{2}\right)
$$

This equation was used to calculate $z^{-1}(r)$ and then $r_{0}^{\prime}$ for the parameters used in the numerical simulations presented in Fig. 3. The value determined for $r_{0}^{\prime}(2.165 \mathrm{~mm})$ was in the excellent agreement with the numerical simulations shown in Fig. 3. This reinforces the hypothesis about independence of $r_{0}^{\prime}$ on the electrode kinetics in the high frequency domain i.e under primary potential distribution conditions.

\subsubsection{Influence of the size of the bi-microelectrode and its position on the derivative of local admit- tance}

Fig. 4a shows $r_{0}^{\prime}$ as a function of $r_{0}$ with the distance between the probe and the WE $(h)$ as a parameter. Each of the 4 curves, obtained for $h$ varying between $50 \mu \mathrm{m}$ and $5 \mathrm{~mm}$, has identical behavior: a linear region with a slope of 1 starting at about $r_{0} \geq h$ and a region with a constant $r_{0}^{\prime}$ value for $r_{0}<h$. These simulations show that the spatial quantification in LEIM is not possible if the radius of the WE is smaller than the distance between the probe and the WE.

The difference $\left(r_{0}-r_{0}^{\prime}\right)$ is plotted as a function of $r_{0}$ in Fig. $4 \mathrm{~b}$ in order to find the precise relation between $r_{0}$ and $r_{0}^{\prime}$ in the form of

$$
r_{0}=r_{0}^{\prime}+b
$$

Fig. $4 \mathrm{~b}$ shows that $b$ is always positive and constant for $r_{0} \geq 10 h$. These curves allow to evaluate the absolute error in the $r_{0}$ determination. For instance, if $h \leq r_{0} \leq 10 h$, the error for the $r_{0}$ estimation can reach $25 \%$. Thus, the ideal experimental conditions are $r_{0} \geq 10 h$, where there is no error in $b$ estimation coming from the deviation of $r_{0}\left(r_{0}^{\prime}\right)$. However, from the experimental point of view it can be complicated or even impossible due to the finite diameter of the probe used for this kind of experiments and the difficulty to maintain a constant distance between the probe and the WE over a large surface area during the mapping.

The variation of the distance $d$ between the microelectrodes in the bi-probe does not change the form of Eq. 13 at $r_{0} \geq h$ but only the value of $b$. Fig. $4 \mathrm{c}$ shows the variations of $b$ as a function of $h$ with $d$ as a parameter. $b$ is a linear function of $h$ at any $d$, indicating that in principle the spatial quantification in LEIM experiments is possible for any distance between the two microelectrodes 
even for the case when a single probe is used. In the real LEIM experiment, the estimation of $h$ remains difficult because of the surface topography and/or the variation of the probe position during mapping (it should be mentioned that to date, no system for an accurate position control has been reported in the literature).

Even though all presented simulations correspond to the primary potential distribution conditions at high $K$, the considered above $r_{0}\left(r_{0}^{\prime}\right)$ relation remains valid for the experiments performed at lower $K$ values (data not shown).

\subsection{Calibration of the quantitative LEIM}

The experimental verifications of numerical simulations were performed for $f=1 \mathrm{kHz}, d=1.0$ $\mathrm{mm}, h=150 \pm 25 \mu \mathrm{m}$ for $\mathrm{Zn}$ electrodes covered with an insulating adhesive tape leaving an active surface of known diameter. The surface of Zn electrodes was washed with $1 \mathrm{M} \mathrm{NaOH}$ for 30 s prior to each calibration measurement to guarantee similar surface state for each experiment. Excellent agreement between numerical simulations and experimental values for the spatial calibration is shown in Fig. 5, which indicates that it is possible to evaluate with a good accuracy the active surface area using LEIM technique. For $r_{0}<h, r_{0}^{\prime}$ is constant and insensitive to $r_{0}$ variations. When $r_{0} \geq h$, a linear relationship between $r_{0}$ and $r_{0}^{\prime}$ is observed. The experimental error for such an approximation for $r_{0} \geq 1 \mathrm{~mm}$ is about $\pm 20 \mu \mathrm{m}$. Similar accuracy was reported for the commercially available Scanning Kelvin Probe technique [30, 31].

Quantitative LEIM methodology can be used to investigate more complex shapes. Fig. 6 shows an example of the definition of the size of an electrochemical system that consisted of two superimposed disks of different diameter. Fig. $6 \mathrm{~b}$ shows the gradient of the admittance for $h=0.5$ $\mathrm{mm}$. The extrema of the gradient closely follow the actual shape of the WE when $h$ is smaller than the radius of each disks $\left(r_{1}=1.5 \mathrm{~mm}\right.$ and $\left.r_{2}=1.0 \mathrm{~mm}\right)$ and only a small deviation near the intersection of the two disks is visible. This can be due to, at least partially, the $d=1.0 \mathrm{~mm}$ and $D=200 \mu \mathrm{m}$ size of microelectrodes in the bi-probe.

When the probe-to-sample distance is increased (Fig. 6c) at $r_{2}<h=1500 \mu \mathrm{m}<r_{1}$, the extrema of the admittance gradient closely follow the shape of the larger disk $\left(r_{1}\right)$, whereas the second one appears to be larger than its actual size. The $r_{0} \geq h$ restriction discussed above on the examples of single disk electrodes is also valid for the superposition of individual disks leading to a complex shape. For the WE with a random shape one should expect the LEIM response represented by the superposition of the circles with the largest possible radii that allows to inscribe them in this random shape. 


\subsection{Application of the spatially resolved LEIM to the delamination on $\mathrm{Zn}$ in $\mathrm{NaCl}$}

In the previous section LEIM methodology was elaborated to define the precise size of the WE immersed in the conductive electrolyte. In the following, this methodology is used to follow the propagation of the electrochemically active zones beneath the polymer at the metal/polymer interface on the example of the model PVB polymer preliminary saturated with the surrounding electrolyte.

It is worth reminding the general limitations on the application of LEIM to polymer coated samples under immersion. If it is not impregnated by the surrounding electrolyte, the polymer can act like an electrical insulator. It shields the ionic flow during AC perturbation thus, avoiding any detection by the LEIM local bi-probe. Preliminary saturation of the polymer increases its conductivity and removes this restriction. When impregnated with surrounding electrolyte, the conductivity of polymer such as PVB should be close to the conductivity of the surrounding electrolyte due to its high porosity and therefore, the presence of the model polymers is not expected to change the spreading of current lines and influence detection in LEIM.

\subsubsection{Methodology}

The applicability of the quantitative LEIM methodology for the investigation of metal corrosion underneath the organic polymer was performed experimentally by investigating the delamination of the PVB polymer away from the artificial defect on Zn. Typical LEIM results are presented in Fig. 7. Fig. 7a shows the optical observation of the sample after 6 hours of exposure in humidified atmosphere with a $1 \mu \mathrm{L}$ drop of $0.5 \mathrm{M} \mathrm{NaCl}$ in the artificial defect. The transparent PVB polymer coating doped with phenolphthalein changes to pink in the vicinity of the artificial defect due to the local $\mathrm{pH}$ increase at the metal/polymer interface, which was attributed to the local oxygen reduction beneath the polymer.

$$
\mathrm{O}_{2}+2 \mathrm{H}_{2} \mathrm{O}+4 \mathrm{e}^{-} \rightarrow 4 \mathrm{OH}^{-}
$$

Therefore, the front of the color change can be attributed to the frontier of cathodic active zone beneath the polymer.

The admittance map of the sample in Fig. 7a is given in Fig. 7b. The modulus of the gradient map is shown in Fig. 7c. Fig. 7d shows the same data as in Fig. 7c but after the low-pass filter treatment and the correction of the position of the maxima according to the calibration curve in Fig. 5. The suitable cut-off frequency was chosen manually for each set of data to ensure only the elimination of noise. The typical value was about $4 \mathrm{~mm}^{-1}$. The treatment in Fig. $7 \mathrm{c}-\mathrm{d}$ was realized 
with the home-made software. The position of the maxima in Fig. 7d relative to the center of the artificial defect was ascribed to the border of the electrochemically active region beneath the polymer. In the following, it will be referred as the front of LEIM based detection of electrochemical zone beneath the polymer or, shorter, by the electrochemical front defined by LEIM $\left(r_{d}\right)$.

\subsubsection{Comparison between the cathodic and electrochemical fronts defined by LEIM}

Fig. 8 shows the kinetics of the propogation of the cathodic and the electrochemical fronts defined by LEIM in the double logarithmic scale. Both curves have the slope of about 0.5. The slope of the propagation of the cathodic front is in agreement with the previous works on the delamination on $\mathrm{Zn}$ [32]. However, the absolute position of the cathodic front is more than 10 times larger than for the electrochemical front defined by LEIM. Fig. 9a shows the optical observation of the surface of the sample after 49 hours of exposure to the humidified atmosphere overlayed with the position of both fronts. The polymer was removed to analyze the surface beneath the polymer. Two distinct regions can be distinguished from the observation of the surface morphology in Fig. 9b. The first region is located within the electrochemical front defined by LEIM with a homogeneous distribution of Zn corrosion products. The morphology of Zn corrosion products was similar to the structure of the Simonkolleite $\left(\mathrm{Zn}_{5}(\mathrm{OH})_{8} \mathrm{Cl}_{2} \times \mathrm{H}_{2} \mathrm{O}\right.$.) [33], which was confirmed by Raman analysis with the two characteristic peaks at $3450 \mathrm{~cm}^{-1}$ and $3490 \mathrm{~cm}^{-1}$ [34]. The second region in Fig. $9 \mathrm{~b}$ is located between cathodic front and the electrochemical front defined by LEIM. The surface morphology in this zone looked similar to a non attacked Zn surface. Raman analysis revealed the presence of $\mathrm{ZnO}$ (Wurtzite crystal structure) with the characteristic peaks at $330 \mathrm{~cm}^{-1}, 435 \mathrm{~cm}^{-1}$ and $1070 \mathrm{~cm}^{-1}$ [34], and $\mathrm{Zn}_{(1+x)} \mathrm{O}$ defective black oxide with the characteristic peak at $570 \mathrm{~cm}^{-1}$ $[35]$.

Fig. 10 shows the position of the electrochemical front defined by LEIM under different applied anodic potentials overlayed with the visual position of the electrochemical front mentioned above as the cathodic front. $r_{d}$ is constant from -0.9 volt (corresponding to the OCP) to -0.3 volt vs $\mathrm{Ag} / \mathrm{AgCl}$ sat. However, between -0.1 volt and 0.1 volt vs $\mathrm{Ag} / \mathrm{AgCl}$ sat., $r_{d}$ moves to the visual position of the electrochemical front and remains at the same level. At such huge anodic potentials, all surface beneath the partially delaminated Zn substrate should become anodically active.

\section{Discussion}

\subsection{Optimal frequency for the quantitative LEIM methodology}

For values of $K$ high enough to reach the primary potential distribution condition, the LEIM electrochemical response reflects only the potential drop due to the ohmic resistance of the elec- 
trolyte. Simulations presented in Fig. 3 showed that one needs to work at $K>10^{3}$ to reach this condition, which corresponds to $f>10^{5} \mathrm{~Hz}$ in our experimental conditions (Fig. 3, upper axis). Under these conditions $r_{0}^{\prime}$ depends exclusively on $r_{0}$ and not on the electrode kinetics of the WE (Fig. 3). This means that only technical limitations of the LEIM instrumentation should limit the error of $r_{0}^{\prime}$ definition. For the present state-of-the art configuration one can possibly reach several $\mu \mathrm{m}$ precision of the spatial quantification in LEIM comparable with the AC-SECM technique [1].

For $K<10^{3}$, the electrode kinetics contributes to the LEIM electrochemical response. The major advantage of this mode is that inhomogeneities in the distribution of the electrochemically active regions can be detected on the surface of the WE. For instance cathodic and anodic zones on the WE can be possible distinguished. The disadvantage is that in this case $r_{0}^{\prime}$ depends on both the applied frequency and the values of $R$ and $C$ on the WE (Fig. 3a). This will contribute to the error of $r_{0}^{\prime}$ definition in successive measurements for the dynamically evolving system.

Fig. 3a for the parallel RC element shows that the minimum of $r_{0}^{\prime}$ variation is less than $40 \mu \mathrm{m}$ at $K \leq 10$ that converts to $f \leq 10^{3} \mathrm{~Hz}$. This means that the error of $r_{0}^{\prime}$ definition at fixed $f$ in the worst case should be about $40 \mu \mathrm{m}$ if there is no error coming from the LEIM instrumentation. In theory, a precision of several micrometers can be reached as in the case of primary potential distribution for the system with stable $R$ and $C$ values for successive measurements. These conclusions are valid only for $\mathrm{RC}$ or RQ parallel elements, that describe the electrode kinetics of dissolving metal at sufficiently high frequencies. The reasonable value of $1 \mathrm{kHz}$ should be low enough to provide minimum deviation of $r_{0}^{\prime}$ and high enough to guarantee that electrode kinetics is described by the $\mathrm{RC}$ parallel element.

\subsection{Origin of the electrochemical response for the cathodic driven delamination under AC pertur-} bation

Fürbeth et al. [32, 36] described the delamination of Zn coated with a model polymer coating by the cathodic delamination mechanism presented in Fig. 11a. In this case, the oxygen reduction reaction drives the delamination of the polymer, whereas the $\mathrm{Zn}$ dissolution occurs in the vicinity of the artificial defect. Cations from the media diffuse to the delamination front to balance the migration of the charge in the galvanic couple between the zone of $\mathrm{Zn}$ dissolution (or anodic zone) and the zone of oxygen reduction (or cathodic zone). The diffusion of cations is the rate limiting step that defines 0.5 slope of the propagation of cathodic front.

The kinetic results of the time-lapse observation of the propagation of the $\mathrm{pH}$ increase underneath the PVB coating (Fig. 8 curve 1 and Fig. 9) are in a good agreement with this mechanism. Observation of the surface morphology beneath the polymer on the delaminated Zn substrate showed 
that the LEIM front at $1 \mathrm{kHz}$ correlates with the regions of $\mathrm{Zn}(\mathrm{II})$ precipitated products. This shows that the LEIM front corresponds only to the anodic zone shown in Fig. 11a.

Fig. 11b shows the partial polarization curves of elemental Zn oxidation and $\mathrm{O}_{2}$ reduction taken for the $\mathrm{Zn}$ dissolution in $0.1 \mathrm{M} \mathrm{NH}_{4} \mathrm{Cl}$ from [37]. The IR drop represents the voltage drop between anodic and cathodic zones due to the ohmic resistance of the electrolyte. As shown in Fig. 11b, the application of small-amplitude sine-wave potential perturbations to the system causes significant variations of the partial $\mathrm{Zn}$ current in the anodic zone and almost no variation of $\mathrm{O}_{2}$ reduction current in the cathodic zone. The absence of response of the cathodic zone can explain why LEIM response reflected only the position of the anodic domain. The results in Fig. 10 reinforce the hypothesis of the detection of only anodically active zones beneath the polymer with the LEIM technique.

In this vein, the delamination data in Fig. 8 can be interpreted as the comparison of the propagation of cathodic and anodic fronts beneath the polymer. It is interesting to note that both of these fronts follow square root of time law. This suggests that both of these phenomena are limited by the same process, i.e. the diffusion of cations to the delamination front.

\section{Conclusions}

In the first part of this work the extrema of the first derivative of local admittance values from the Local Electrochemical Impedance Mapping (LEIM) were shown to closely correlate with the size of active zones on the working electrode (WE). It was shown that the LEIM can be used as a tool for the quantification of the size of electrochemically active regions on the WE. In addition, numerical simulations of the potential distribution allowed to define the optimal conditions for the application of the quantitative LEIM methodology. It was shown that the precision for the quantification of the size is mainly governed by the sensibility of the experimental equipments. An error of only several micrometers can be accessible with the present state-of-the-art apparatus.

In the second part the quantitative LEIM methodology was successfully applied to follow the delamination kinetics on Zn covered with the PVB polymer. In this case, LEIM was sensitive only to the position of the anodic front. The comparison between optical and electrochemical observations shows the complementarity of these two measurements.

This novel LEIM methodology appears to be a promising tool to follow quantitatively the delamination kinetics of polymer coated metals applied to the samples immersed in conductive solutions. It is worth noting that it differs from the existent Scanning Kelvin Probe methodology used to follow the delamination kinetics under atmospheric conditions. 


\section{Acknowledgments}

The authors acknowledge Safran Landing Systems for the financial support. 


\section{References}

[1] M. Lucas, J. F. Boily, Mapping Electrochemical Heterogeneity at Iron Oxide Surfaces: A Local Electrochemical Impedance Study, Langmuir 31 (50) (2015) 13618-13624. doi:10.1021/acs.langmuir.5b03849.

[2] A. S. Bandarenka, K. Eckhard, A. Maljusch, W. Schuhmann, Localized electrochemical impedance spectroscopy: Visualization of spatial distributions of the key parameters describing solid/liquid interfaces, Analytical Chemistry 85 (4) (2013) 2443-2448. doi:10.1021/ac303490t.

[3] Y. Takahashi, A. Kumatani, H. Munakata, H. Inomata, K. Ito, K. Ino, H. Shiku, P. R. Unwin, Y. E. Korchev, K. Kanamura, T. Matsue, Nanoscale visualization of redox activity at lithiumion battery cathodes, Nature Communications 5 (2014) 1-7. doi:10.1038/ncomms6450.

[4] D. Trinh, M. Keddam, X. R. Nóvoa, V. Vivier, Characterization of adsorbates by transient measurements in Scanning Electrochemical Microscopy, Electrochimica Acta 131 (2014) 28-35. doi:10.1016/j.electacta.2014.02.002.

[5] J. Izquierdo, B. M. Fernández-Pérez, A. Eifert, R. M. Souto, C. Kranz, Simultaneous Atomic Force-Scanning Electrochemical Microscopy (AFM-SECM) Imaging of Copper Dissolution, Electrochimica Acta 201 (2016) 320-332. doi:10.1016/j.electacta.2015.12.160.

[6] R. T. Kurulugama, D. O. Wipf, S. A. Takacs, S. Pongmayteegul, P. A. Garris, J. E. Baur, Scanning electrochemical microscopy of model neurons: Constant distance imaging, Analytical Chemistry 77 (4) (2005) 1111-1117. doi:10.1021/ac048571n.

[7] J. B. Jorcin, E. Aragon, C. Merlatti, N. Pébère, Delaminated areas beneath organic coating: A local electrochemical impedance approach, Corrosion Science 48 (2006) 1779-1790. doi:10.1016/j.corsci.2005.05.031.

[8] V. M. Huang, S.-L. Wu, M. E. Orazem, N. Pébère, B. Tribollet, V. Vivier, Local electrochemical impedance spectroscopy: A review and some recent developments, Electrochimica Acta 56 (23) (2011) 8048-8057. doi:10.1016/j.electacta.2011.03.018.

[9] A. W. Hassel, A. I. Mardare, Localised electrochemical impedance spectroscopy using a scanning droplet cell microscope, Journal of Electroanalytical Chemistry 737 (2015) 93-99. doi:10.1016/j.jelechem.2014.07.007. 
[10] J. Kwak, A. J. Bard, Scanning electrochemical microscopy. Apparatus and two-dimensional scans of conductive and insulating substrates, Analytical Chemistry 61 (1989) 1794-9. doi:10.1021/ja3106434.

[11] P. M. Diakowski, A. S. Baranski, Positive and negative AC impedance feedback observed above conductive substrates under SECM conditions, Electrochimica Acta 52 (3) (2006) 854-862. doi:10.1016/j.electacta.2006.06.020.

[12] F. Zou, D. Thierry, H. S. Isaacs, A High-Resolution Probe for Localized Electrochemical Impedance Spectroscopy Measurements, Journal of The Electrochemical Society 144 (6) (1997) 1957-1965. doi:10.1149/1.1837729.

[13] A. M. Mierisch, S. R. Taylor, V. Celli, Understanding the Degradation of Organic Coatings Through Local Electrochemical Impedance Methods. II. Moddeling and Experimental Results of Normal Field Variations above Disk Electrodes., Journal of The Electrochemical Society 150 (7) (2003) B309-B315. doi:10.1149/1.1576224.

[14] V. Vivier, M. d. A. Camila, C. P. Abreu, I. Costa, H. G. de Melo, M. Keddam, Influence of Probe Size and Probe Position for Local Electrochemical Impedance Spectroscopy, Meeting Abstracts MA2015-02 (49) (2015) 1941-1941.

[15] R. S. Lillard, P. J. Moran, H. S. Isaacs, A Novel Method for Generating Quantitative Local Electrochemical Impedance Spectroscopy, Journal of The Electrochemical Society 139 (4) (1992) 1007-1012. doi:10.1149/1.2069332.

[16] M. W. Wittmann, R. Leggat, S. R. Taylor, The Detection And Mapping Of Defects In Organic Coatings Using Local Electrochemical Impedance Methods, Journal of The Electrochemical Society 146 (11) (1999) 4071-4075. doi:10.1557/PROC-411-31.

[17] L. V. S. Philippe, G. W. Walter, S. B. Lyon, Investigating Localized Degradation of Organic Coatings, Journal of The Electrochemical Society 150 (4) (2003) B111-B119. doi:10.1149/1.1554913.

[18] A. M. Mierisch, S. R. Taylor, V. Celli, Understanding the Degradation of Organic Coatings Through Local Electrochemical Impedance Methods. I. Commonly Observed Features., Journal of The Electrochemical Society 150 (7) (2003) B303-B308. doi:10.1149/1.1576224.

[19] J. Newman, Frequency Dispersion in Capacity Measurements at a Disk Electrode, Journal of The Electrochemical Society 117 (2) (1970) 198-203. doi:10.1149/1.2407464. 
[20] C. Blanc, M. E. Orazem, N. Pébère, B. Tribollet, V. Vivier, S. Wu, The origin of the complex character of the Ohmic impedance, Electrochimica Acta 55 (21) (2010) 6313-6321. doi:10.1016/j.electacta.2010.04.036.

[21] V. M.-W. Huang, V. Vivier, M. E. Orazem, N. Pébère, B. Tribollet, The Apparent ConstantPhase-Element Behavior of an Ideally Polarized Blocking Electrode. A Global and Local Impedance Analysis, Journal of The Electrochemical Society 154 (4) (2007) C81-C88. doi:10.1149/1.2558713.

[22] V. M.-W. Huang, V. Vivier, I. Frateur, M. E. Orazem, B. Tribollet, The Global and Local Impedance Response of a Blocking Disk Electrode with Local Constant-Phase-Element Behavior, Journal of The Electrochemical Society 154 (2007) C89-C98. doi:10.1149/1.2398889.

[23] V. M.-W. Huang, V. Vivier, M. E. Orazem, N. Pébère, B. Tribollet, The Apparent ConstantPhase-Element Behavior of a Disk Electrode with Faradaic Reactions, Journal of The Electrochemical Society 154 (2007) C99-C107. doi:10.1149/1.2398894.

[24] I. Frateur, V. M.-W. Huang, M. E. Orazem, B. Tribollet, V. Vivier, Experimental Issues Associated with Measurement of Local Electrochemical Impedance, Journal of The Electrochemical Society 154 (12) (2007) C719-C727. doi:10.1149/1.2789292.

[25] I. Frateur, V. M.-W. Huang, M. E. Orazem, B. Tribollet, V. Vivier, Local electrochemical impedance spectroscopy: Considerations about the cell geometry, Electrochimica Acta 53 (2008) 7386-7395. doi:10.1016/j.electacta.2008.01.012.

[26] J. Newman, Resistance for flow of current to a disk, Journal of The Electrochemical Society 113 (1966) 501-502.

[27] V. Shkirskiy, P. Keil, H. Hintze-Bruening, F. Leroux, T. Stimpfling, D. Dragoe, K. Ogle, P. Volovitch, MoO42- as a soluble inhibitor for Zn in neutral and alkaline solutions, Corrosion Science 99 (2015) 31-41. doi:10.1016/j.corsci.2015.05.005.

[28] A. Leng, H. Streckel, M. Stratmann, The delamination of polymeric coatings from steel. Part 2: First stage of delamination, effect of type and concentration of cations on delamination, chemical analysis of the interface, Corrosion Science 41 (3) (1999) 579-597. doi:10.1016/S0010938X(98)00167-X. 
[29] L. Nanis, W. Kesselman, Engineering Applications of Current and Potential Distributions in Disk Electrode Systems, Journal of The Electrochemical Society 118 (3) (1971) 454-461. doi:10.1149/1.2408080.

[30] H. N. McMurray, G. Williams, Probe diameter and probe-specimen distance dependence in the lateral resolution of a scanning Kelvin probe, Journal of Applied Physics 91 (3) (2002) 1673-1679. doi:10.1063/1.1430546.

[31] M. Wicinski, W. Burgstaller, H. Achim, Lateral resolution in scanning Kelvin probe microscopy, Corrosion Science 104 (2016) 1-8. doi:10.1016/j.corsci.2015.09.008.

[32] W. Fürbeth, M. Stratmann, Delamination of polymeric coatings from electrogalvanized steel a mechanistic approach. Part 2: Delamination from a defect down to steel, Corrosion Science 43 (2001) 229-241. doi:10.1016/S0010-938X(00)00048-2.

[33] P. Volovitch, C. Allely, K. Ogle, Understanding corrosion via corrosion product characterization: I. Case study of the role of $\mathrm{Mg}$ alloying in $\mathrm{Zn}-\mathrm{Mg}$ coating on steel, Corrosion Science 51 (6) (2009) 1251-1262. doi:10.1016/j.corsci.2009.03.005.

[34] M. Bernard, A. Hugot-Le Goff, D. Massinon, N. Phillips, Underpaint corrosion of zinc-coated steel sheet studied by in situ raman spectroscopy, Corrosion Science 35 (5-8) (1993) 1339-1349. doi:10.1016/0010-938X(93)90356-L.

[35] Y. Chen, P. Schneider, B.-J. Liu, S. Borodin, B. Ren, A. Erbe, Electronic structure and morphology of dark oxides on zinc generated by electrochemical treatment., Physical Chemistry Chemical Physics 15 (24) (2013) 9812-9822. doi:10.1039/c3cp44714f.

[36] W. Fürbeth, M. Stratmann, The delamination of polymeric coatings from electrogalvanised steel-a mechanistic approach.-Part 1: delamination from a defect with intact zinc layer, Corrosion Science 43 (2001) 207-227. doi:10.1016/S0010-938X(00)00047-0.

[37] V. Shkirskiy, K. Ogle, A novel coupling of electrochemical impedance spectroscopy with atomic emission spectroelectrochemistry: Application to the open circuit dissolution of zinc, Electrochimica Acta 168 (2015) 167-172. doi:10.1016/j.electacta.2015.03.171. 


\section{Figure captions}

Figure 1: Schematic representation of (a) 3D and (b) cross section of the electrochemical cell used for the numerical simulations.

Figure 2: Local admittance $\left(z^{-1}(r)\right)$ as a function of the distance (solid line) from the axis of symmetry and the first derivative of $z^{-1}(r)$ (dotted line). The radius of the WE $\left(r_{0}\right)$ was $2.0 \mathrm{~mm}$. Simulations were performed for $f=1 \mathrm{kHz}, R=1 \mathrm{k} \Omega \mathrm{cm}^{2}, C=50 \mu \mathrm{F} \mathrm{cm} \mathrm{cm}^{-2}, h=0.5 \mathrm{~mm}$ and $d=$ $1.0 \mathrm{~mm}$.

Figure 3: (a) shows the effect of the dimensionless frequency $K$ on $r_{0}^{\prime}$ for the parallel RC element with $R$ value as a parameter: (1) $R=0 \Omega \mathrm{cm}^{2}$ (equivalent of a single capacitor), (2) $R=10 \Omega \mathrm{cm}^{2}$, (3) $R=100 \Omega \mathrm{cm}^{2}$ and (4) $R=1 \mathrm{k} \Omega \mathrm{cm}^{2}$. The upper axis shows the values of $f$ for $C=50 \mu \mathrm{F}$ $\mathrm{cm}^{-2}$. (b) shows the effect of $R$ at $C=0$ on $r_{0}^{\prime}$. Other parameters were identical for (a) and (b): $r_{0}=2.0 \mathrm{~mm}, h=0.5 \mathrm{~mm}$ and $d=1.0 \mathrm{~mm}$.

Figure 4: (a) shows the effect of $r_{0}$ on $r_{0}^{\prime}$ with $h$ as a parameter: (1) $h=5 \mathrm{~mm},(2) h=0.5 \mathrm{~mm},(3)$ $h=50 \mu \mathrm{m}$ and (4) $h=5 \mu \mathrm{m}$. (b) shows $\left(r_{0}-r_{0}^{\prime}\right)$ as a function of $r_{0}$. (c) represents $b$ as a function of $h$ with $d$ value as a parameter: (1) $d \rightarrow \infty$ (equivalent of a single probe), (2) $d=1.0 \mathrm{~mm}$ and (3) $d=10 \mu \mathrm{m}$. All simulations were performed under primary potential distribution conditions.

Figure 5: Correlation between $r_{0}$ and $r_{0}^{\prime}$. Solid line shows the result of numerical simulations for $R=100 \Omega \mathrm{cm}^{2}, C=50 \mu \mathrm{F} \mathrm{cm}{ }^{-2}$. Dots represent experimental results with $\mathrm{Zn}$ electrodes having an exposed surface of known radius. $h=150 \mu \mathrm{m}, d=1.0 \mathrm{~mm}, f=1 \mathrm{kHz}$ parameters were identical for the numerical simulations and experiments. Dash red line shows the linear fit of $r_{0}\left(r_{0}^{\prime}\right)$ for $r_{0} \geq 1.0$ $\mathrm{mm}$. 
Figure 6: (a) Optical image of Zn electrode partially covered with an adhesive tape used to estimate the influence of the distance $(h)$ between the probe and the WE on the quantitative LEIM application. Solid lines represent the superposition of these two disks with $r_{1}=1.5 \mathrm{~mm}$ and $r_{2}=1.0$ mm leaving the active surface area exposed. Figs. (b) and (c) show the gradient of the admittance modulus for (b) $h=0.5 \mathrm{~mm}$ and (c) $h=1.5 \mathrm{~mm}$. Dash lines indicate the extremum of the modulus of the gradient of admittance maps.

Figure 7: An example of the results $(a, b)$ obtained in delamination experiments and the steps of the treatment $(c, d)$. (a) shows the optical image of the Zn surface coated with a transparent PVB polymer containing $5 \mathrm{w} / \mathrm{w} \%$ phenolphthalein. The artificial defect is outlined by the solid white line whereas the dash line indicates the front of the color change of the polymer. (b) shows the admittance map of (a), (c) is the modulus of the gradient of (b). (d) is the same data as in (c) after a low-pass filtering corrected according to the calibration curve in Fig. 5.

Figure 8: Propagation of the average position (1) the optical and (2) LEIM based detection of electrochemical fronts as defined in Fig. 7. The initial position of the delamination front $\left(r_{d}\left(t_{0}\right)\right)$ was subtracted from all data whereas $t_{0}$ was defined as the time of the onset of the delamination (about $1 \mathrm{~h}$ ). Each point represents an average of 3 independent experiments and their standard deviation.

Figure 9: Typical zones observed in delamination experiments after 49 hours of exposure in humidified atmosphere. (a) is the optical image. The black dash line indicates the front of the polymer color change, the white dash line - the position of the electrochemical front defined by LEIM and the solid white line - the position of the artificial defect. (b) shows the SEM image in the vicinity of the electrochemical front defined by LEIM.

Figure 10: Position of the electrochemical front defined by LEIM $\left(r_{d}-r_{d}\left(t_{0}\right)\right)$ as a function of the applied potential for a partially delaminated Zn coated sample. The average position of the polymer color change is $1.0 \mathrm{~mm}$. Application of $V>-0.1 \mathrm{~V}$ shifts $\left(r_{d}-r_{d}\left(t_{0}\right)\right)$ from $0.2 \mathrm{~mm}$ to $1.0 \mathrm{~mm}$. 
Figure 11: Sketch of the LEIM response of a partially delaminated Zn substrate according to [32, 36] (a). Fig. (b) shows $i(V)$ curves of partial anodic and cathodic reactions and their response to the application of an AC perturbation during LEI mapping. Only the anodic part of the galvanic couple beneath the polymer contributes to the LEIM response due to the plateau of the oxygen reduction. Data for (b) were adapted from [27] for the Zn dissolution in $0.1 \mathrm{M} \mathrm{NH}_{4} \mathrm{Cl}$. 


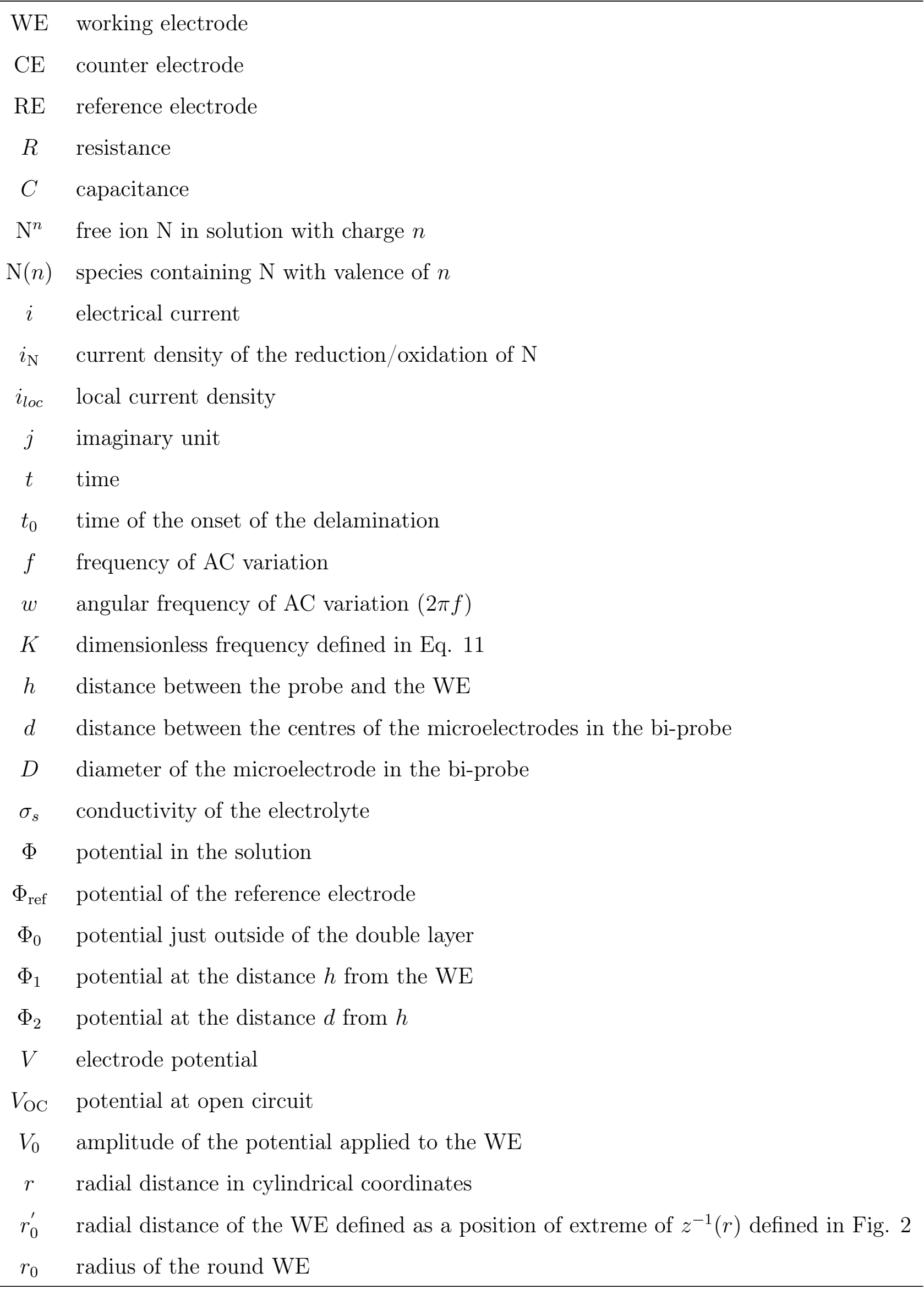




\footnotetext{
$r_{d} \quad$ position of the electrochemical front defined by LEIM

$r_{\mathrm{N}} \quad$ radius of circle $\mathrm{N}$

$\theta \quad$ azimuth in cylindrical coordinates

$y \quad$ normal to the WE axis in cylindrical coordinates

$b \quad$ coefficient of the linear LEIM spatial calibration defined in Eq. 13

$z \quad$ local value of the impedance defined in Eq. 10

$z^{-1} \quad$ local value of the admittance defined as reciprocal of $z$

$X_{C}$ global impedance of the single $\mathrm{C}$
} 
Fig. 1

(a)

(b)
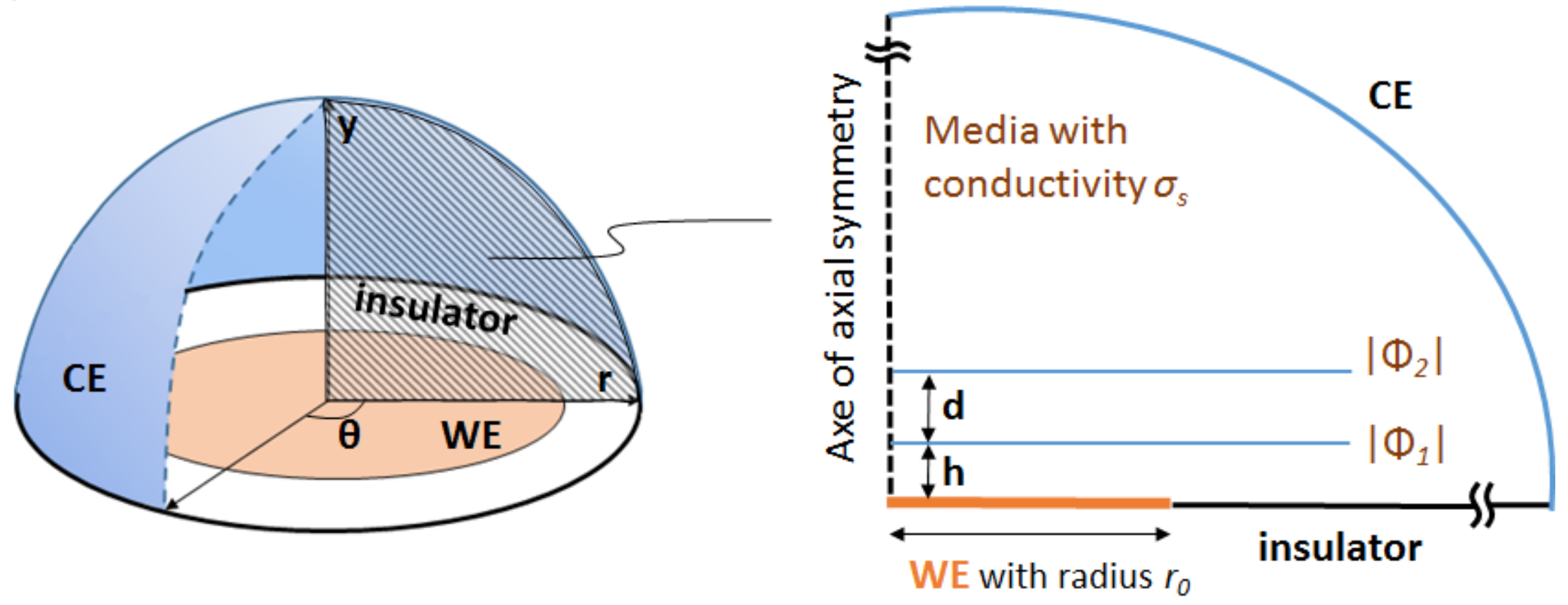
Fig. 2

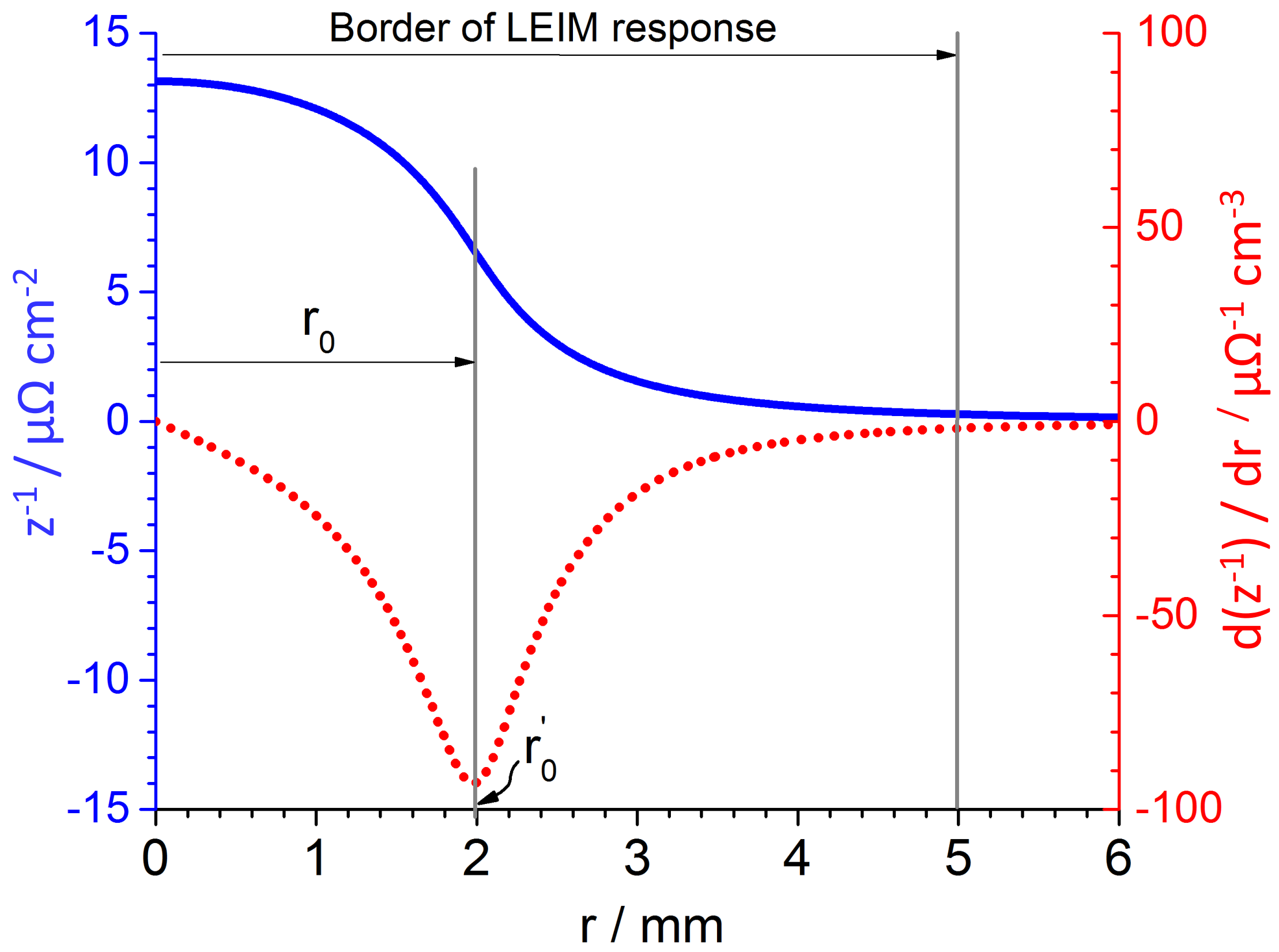


Fig. 3

(a)

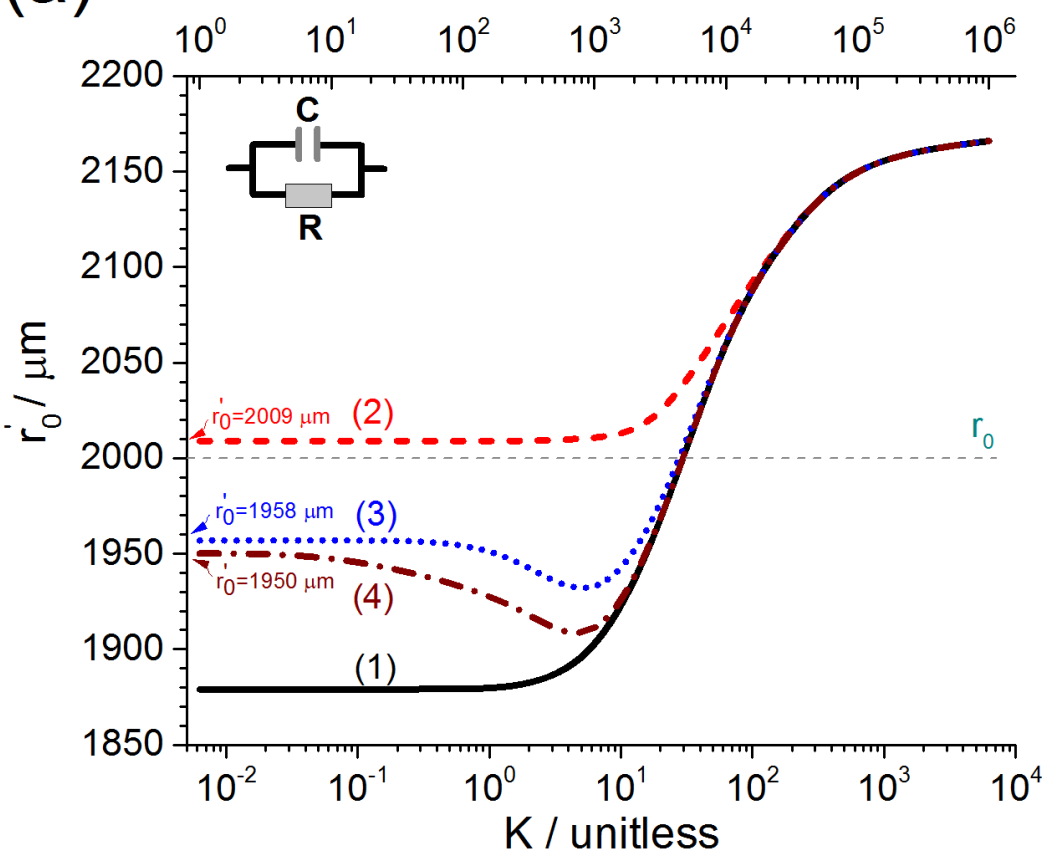

(b)

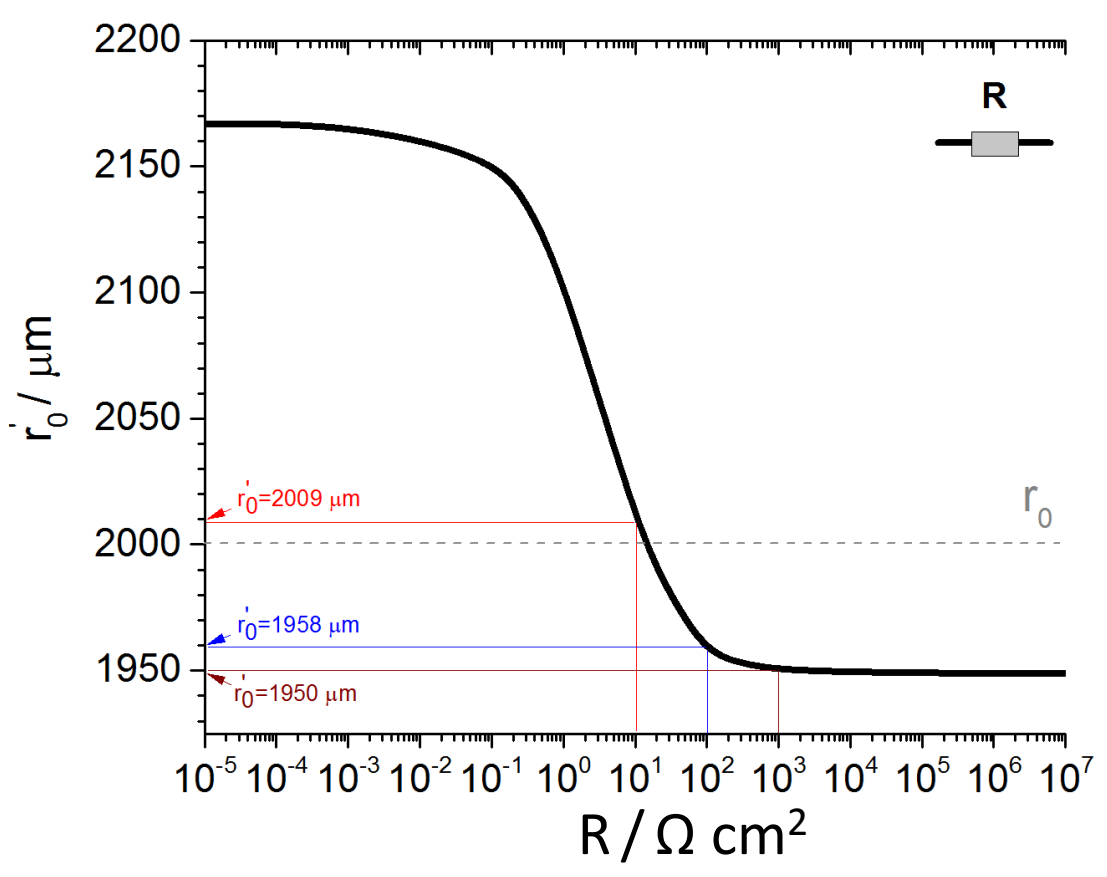


Fig. 4
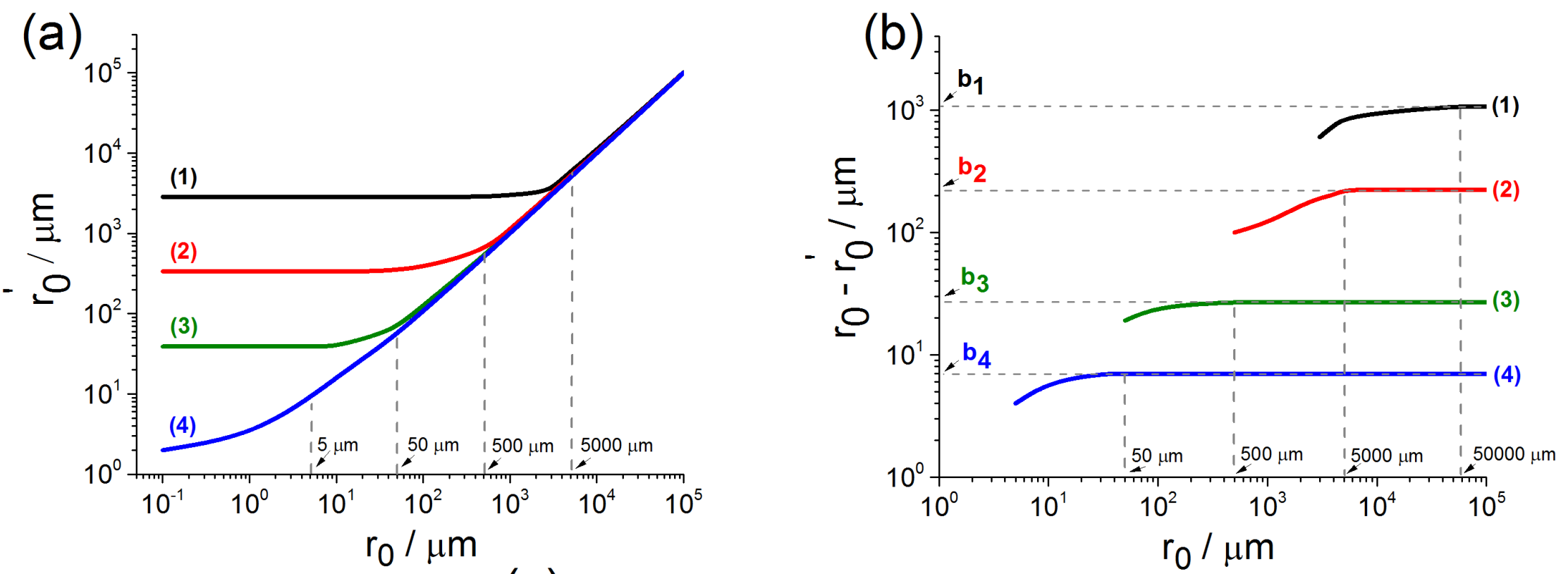

(c)

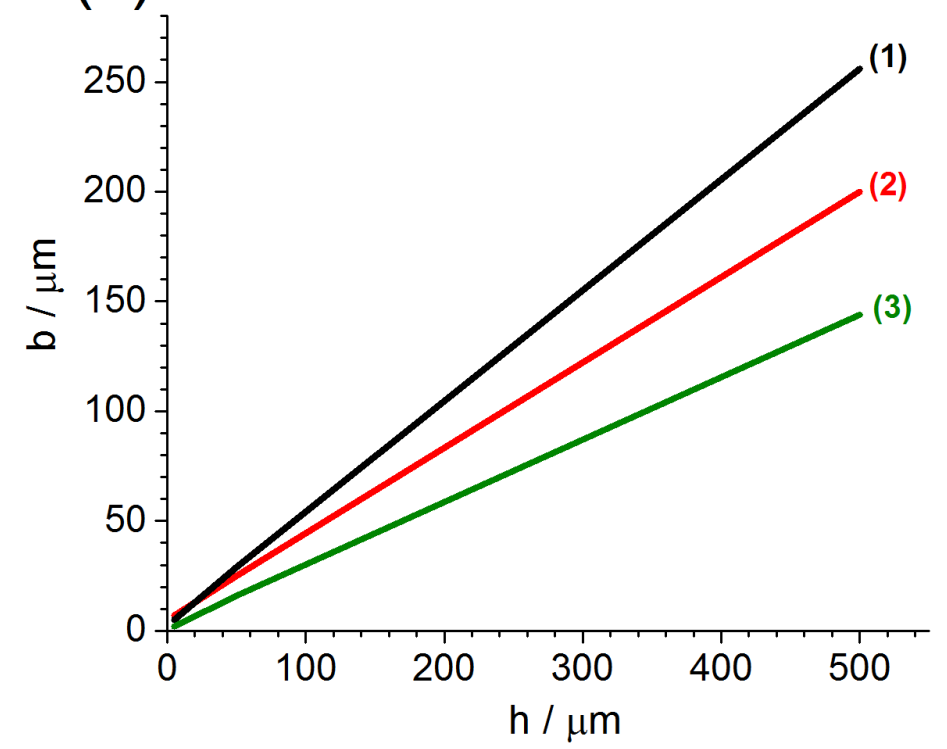


Fig. 5

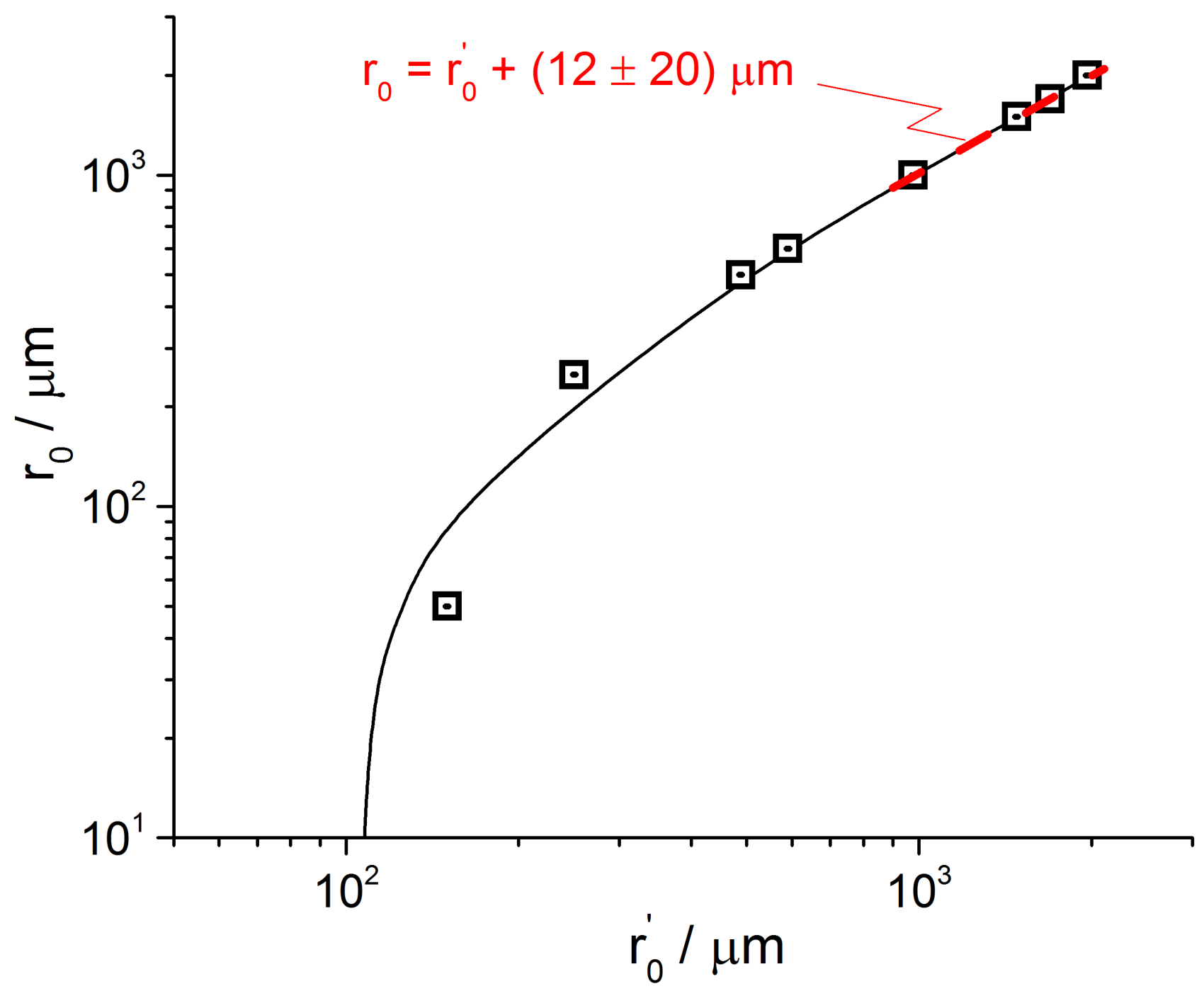


Fig. 6

(a)

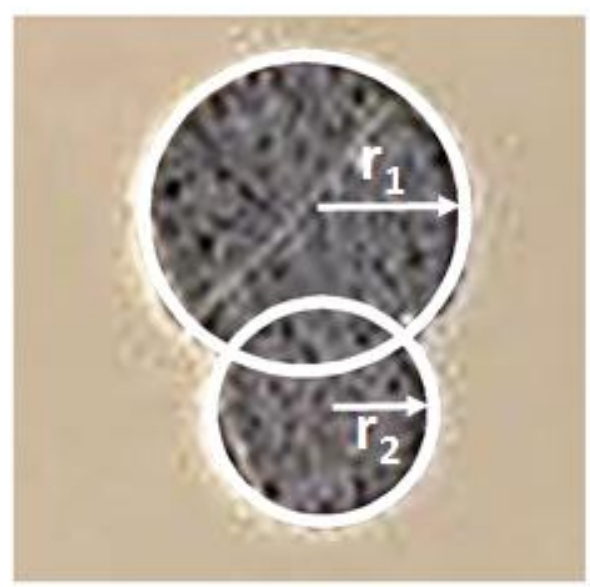

(b)

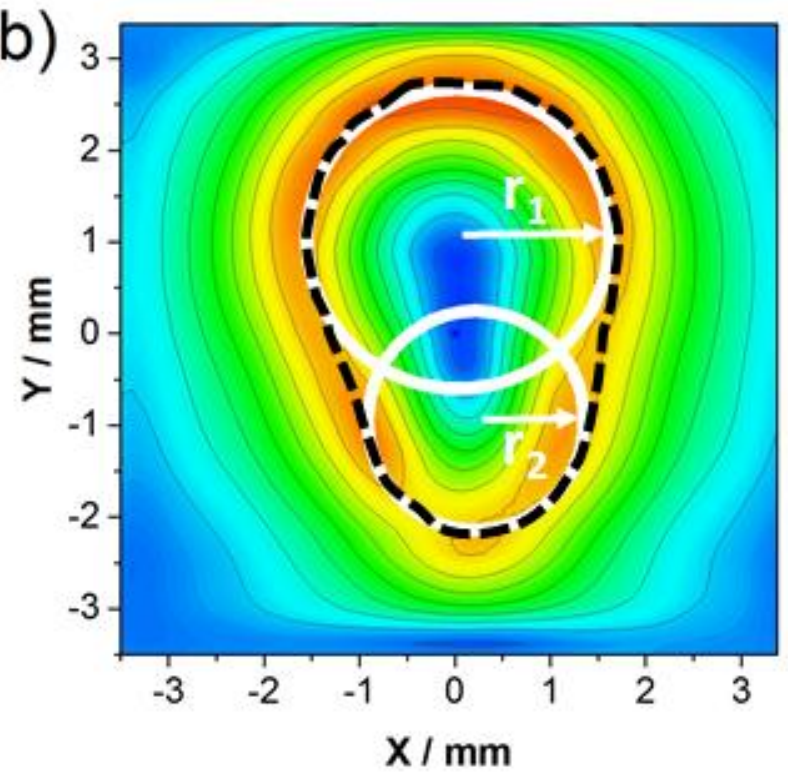

(c)

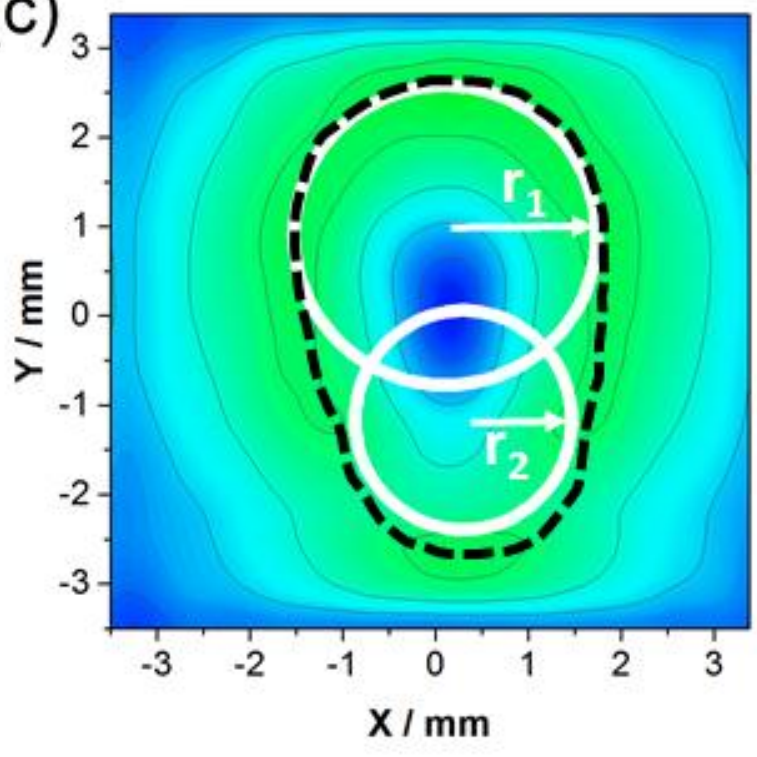

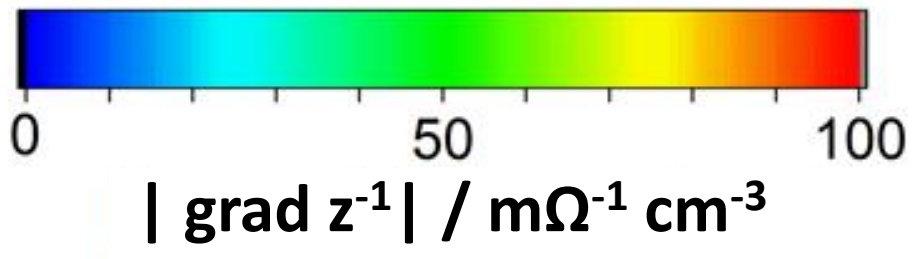


Fig. 7

(a)
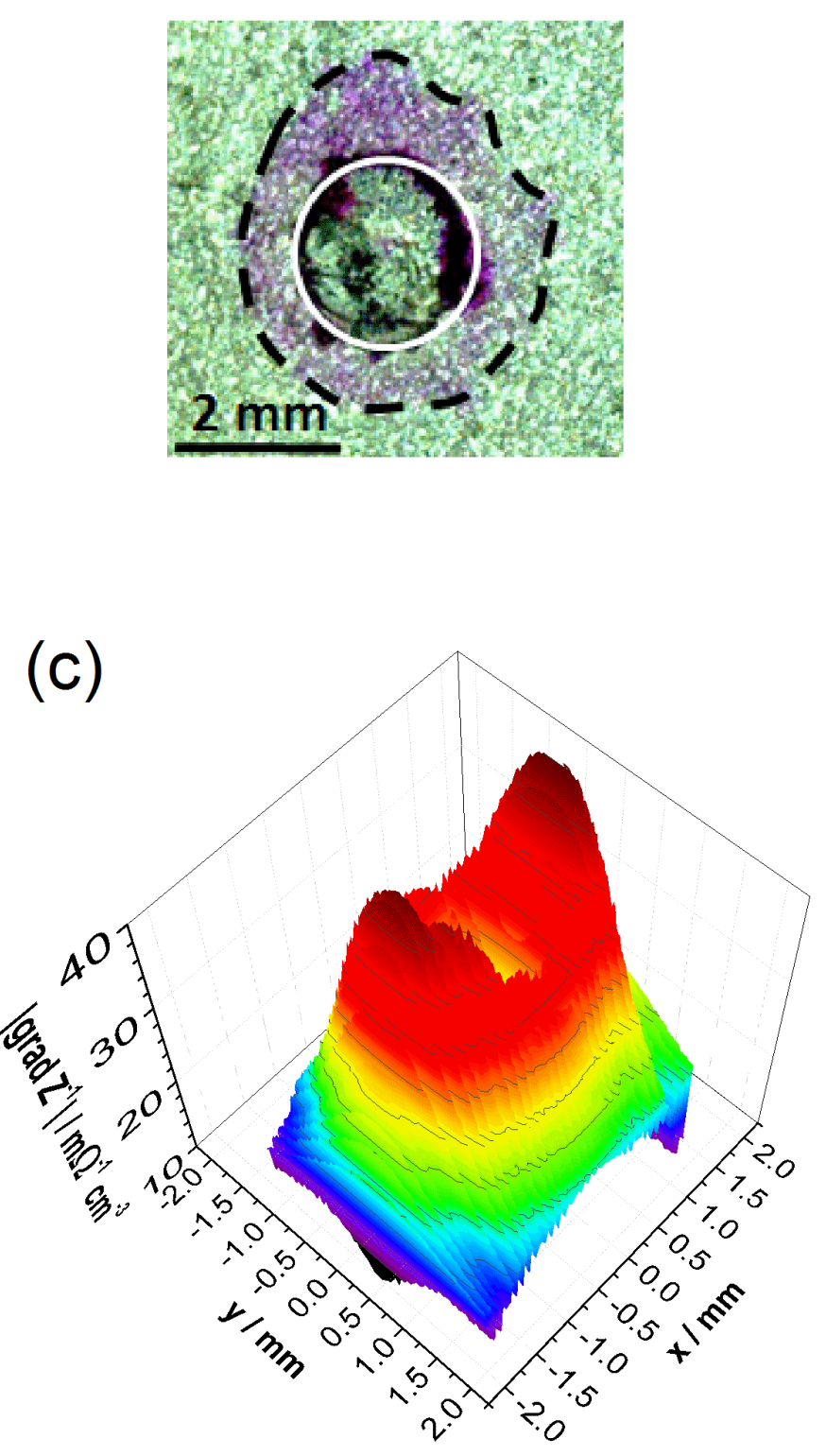

(b)

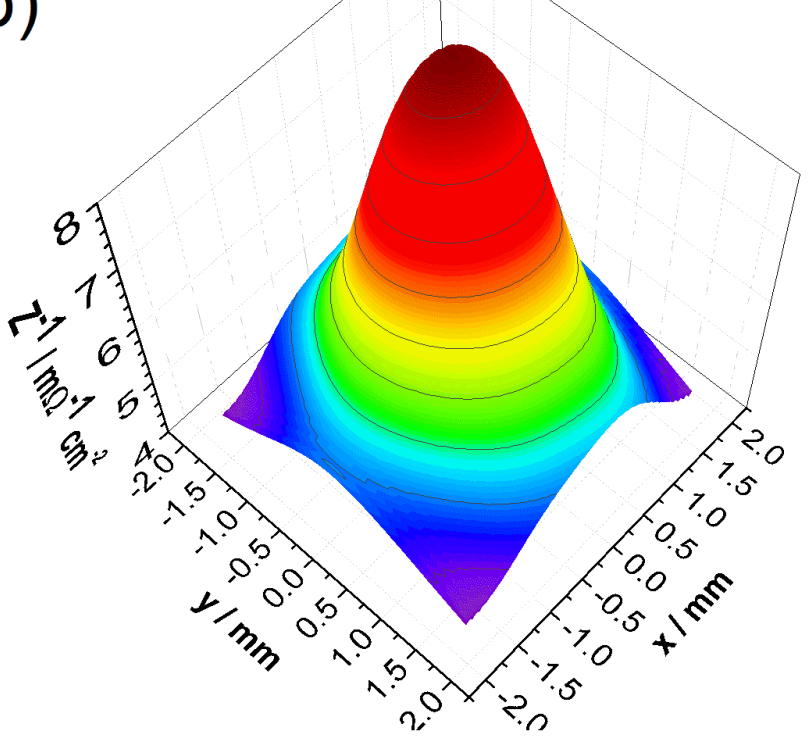

(d)

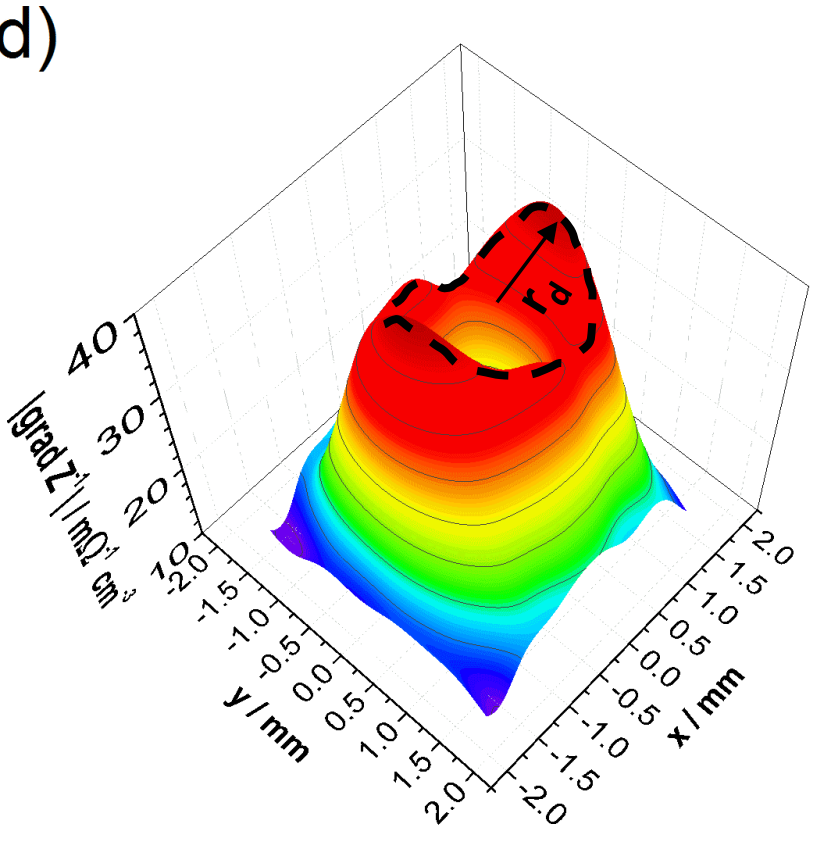


Fig. 8

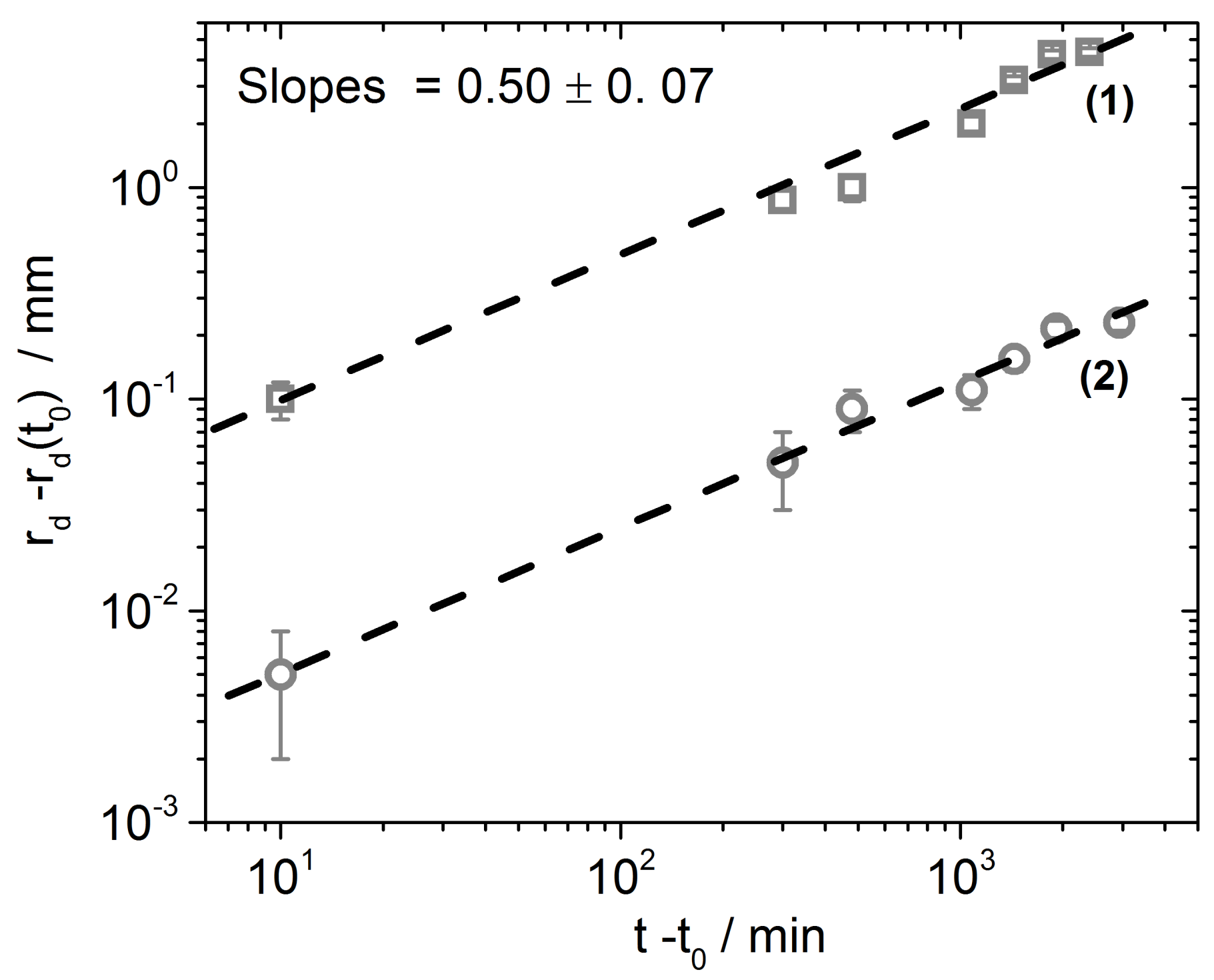


Fig. 9

(a)

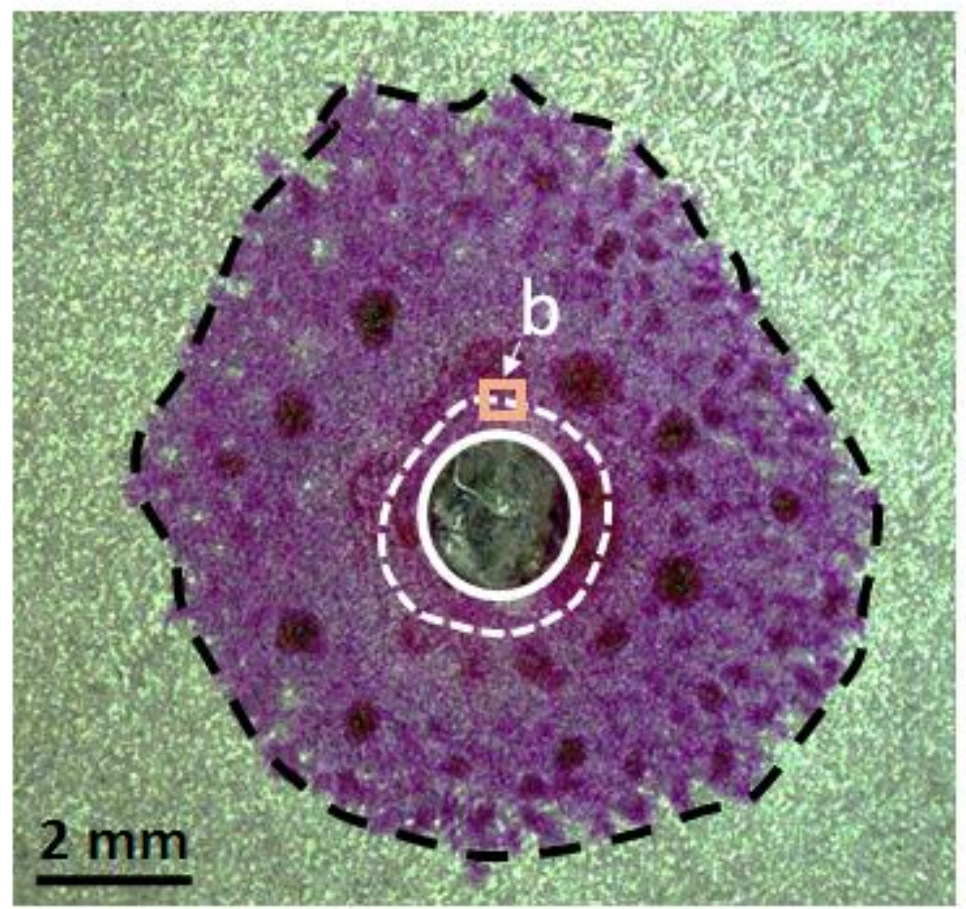

(b)

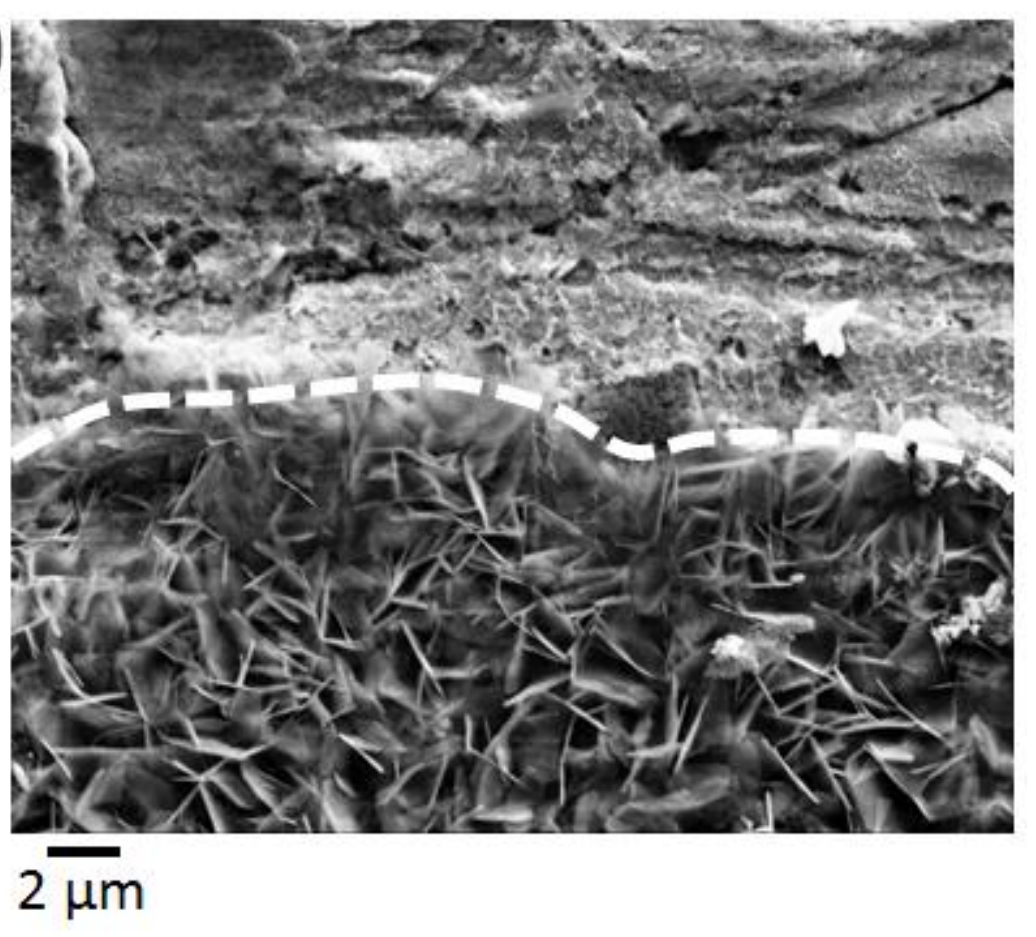


Fig. 10

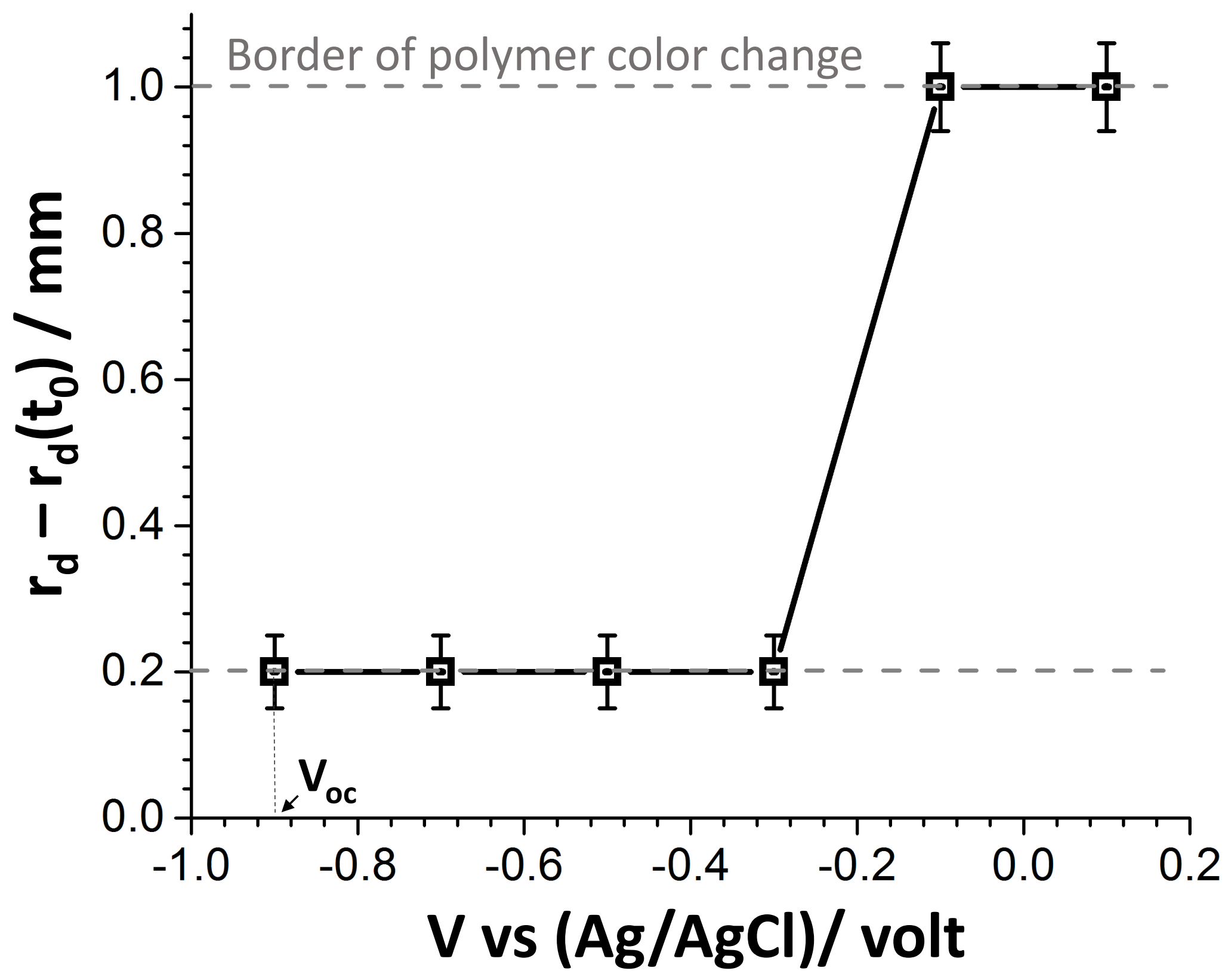


Fig. 11

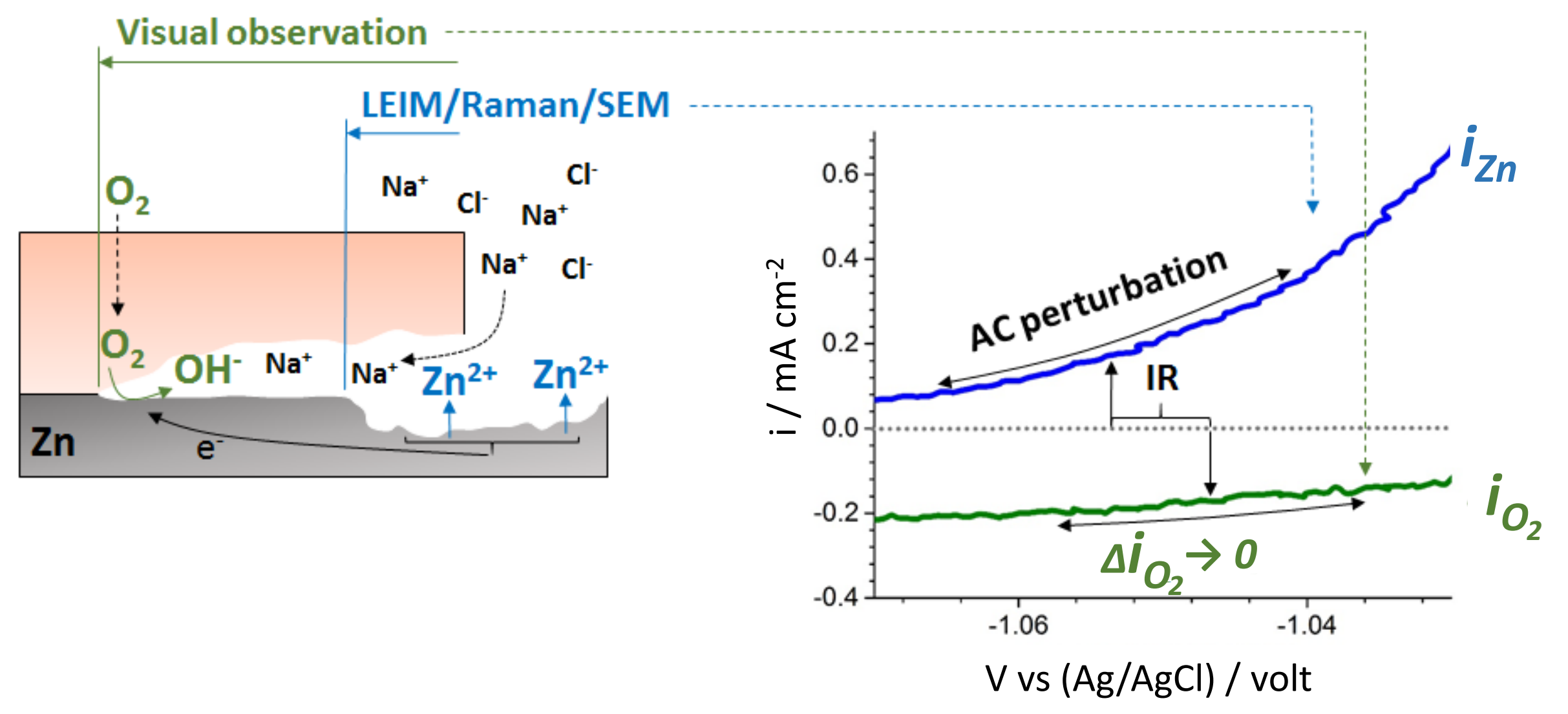

